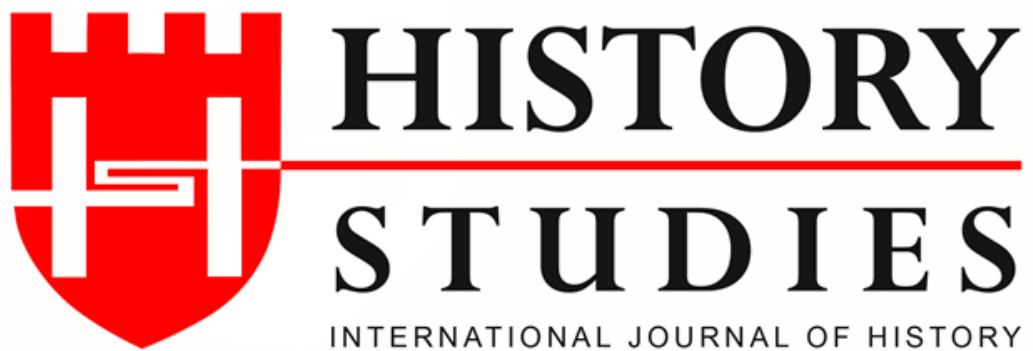

ISSN: 13094173 / (Online) 1309 - 4688 (Print)

Volume: 13, Issue: 4, August 2021

www.historystudies.net

\title{
1949 YILI (Kt. b/k) KÜLTEPE KAZISINDAN ASURLU TÜCCARLARA AITT BİR GRUP TABLET
}

\section{A Group of Tablets Belonging to The Assyrian Merchants From The Kültepe} Excavation in 1949 (Kt. b/k)

\section{Prof. Dr. Salih Çeçen}

Ankara Üniversitesi

cecen@ankara.edu.tr

ORCID ID: 0000-0003-0897-3918

\section{Prof. Dr. L. Gürkan Gökçek}

Nevşehir Hacı Bektaş Veli Üniversitesi

kuregen@hotmail.com

ORCID ID: 0000-0002-1974-7476

\section{Doç. Dr. Koray Toptaş}

Gazi Üniversitesi

koraytoptas@gazi.edu.tr

ORCID ID: 0000-0003-0897-3918

Makale Türü-Article Type Geliș Tarihi-Received Date Kabul Tarihi-Accepted Date DOI Number
Araştırma Makalesi-Research Article

07.03.2021

11.08.2021

10.9737/hist.2021.1026

Atıf-Citation: 

HISTORY STUDIES

Uluslararası Tarih Araştırmaları Dergisi

International Journal of History

13/4, Ağustos - August 2021

1079-1105

Araştırma Makalesi

\title{
1949 YILI (Kt. b/k) KÜLTEPE KAZISINDAN ASURLU TÜCCARLARA AİT BİR GRUP TABLET
}

A Group of Tablets Belonging to The Assyrian Merchants From The Kültepe Excavation in 1949

(Kt. b/k)

\author{
Prof. Dr. Salih Çeçen
}

Prof. Dr. L. Gürkan Gökçek

Doç. Dr. Koray Toptaş

\section{Öz}

Kültepe'de 1948 yılından itibaren yürütülen sistematik kazılarda büyük bir bölümü Asurlu tüccarlara ait çivi yazılı tablet arşivleri ortaya çıkarılmıştır. Bu belgeler Anadolu'nun Eskiçağ Tarihi hakkında bilgi veren en eski yazılı kaynaklardır. Bu tabletlerin hemen hepsi ticari ve hukuki konuları ihtiva etmektedir. Kültepe'de bulunan Eski Asurca tabletlerin büyük çoğunluğunun ticari belgeler olması, bu dönemde Anadolu'daki ticari hayatın detaylı bir şekilde öğrenilmesini mümkün kılmaktadır. Bu çalışmada 1949 yılı kazılarında ele geçirilen 13 tablet ve bunların bazılarına ait zarflar ele alınmıştır. Bu kapsamda çalışmamız, ekonomik, coğrafi, sosyo-kültürel ve prosopografik odaklıdır.

Anahtar Kelimeler: Kültepe, Borç Senedi, Çiviyazısı, Asur Ticaret Kolonileri Devri

\begin{abstract}
In the systematic excavations carried out in Kültepe since 1948, cuneiform tablet archives, most of which belonged to the Assyrian merchants, were unearthed. These documents are the oldest written sources that give information about the Ancient History of Anatolia. Almost all of these tablets contain commercial and legal issues. The fact that the majority of the Old Assyrian tablets found in Kültepe are commercial documents makes it possible to learn in detail the commercial life in Anatolia during this period. In this study, thirteen tablets and envelopes belonging to some of the documents found in the 1949 excavations are discussed. In this context, our work has an economic, geographical, sociocultural and prosopographic focus.
\end{abstract}

Keywords: Kültepe, Debt Contract, Legal Document, Cuneiform, The Old Assyrian Colony Period 


\title{
Giriş
}

Asur Ticaret Kolonileri Çağı (M.Ö. 1970-1750)'na ait belgeler Anadolu'nun ilk yazıll malzemeleri olmaları bakımından Anadolu'nun kültür, ekonomi, sosyal ve siyasi tarihi açısından önemli bir yere sahiptirler. Bu devir yaklaşık olarak 220 yıllık bir dönemi temsil etse de, çıkarılan belgelerin büyük oranda 40-50 yıllık bir zaman aralığına ait olduğunu söylemek gerekir. ${ }^{1}$ Kültepe Tabletleri olarak adlandırılan ve Eski Asur lehçesinde yazılmış bu tabletler incelendiğinde Asurlu tüccarlar ve Anadolu'nun yerli halkı hakkında değerli bilgilere ulaşılmaktadır. Bu yönüyle Kültepe Tabletleri Koloni Devri Anadolu'sunun ve Eski Asur Devleti'nin kültür hayatına ve kısmen siyasi tarihine ilişkin boşlukların doldurulmasında anahtar bir role sahiptir. Ancak tabletlerin orta çıkışı Mezopotamya'da büyük saray arşivlerinin açığa çıkarılmasından çok sonra olmuştur. Kültepe'ye olan ilgi önceleri Kapadokya Tabletleri olarak adlandırılan ve köylüler tarafından kaçak kazılarda çıkarılan tabletlerin yurtdışına götürülmesiyle birlikte ortaya çıkmıştır. Bu vesileyle yabancı araştırmacılar tarafından 18931925 yılları arasında höyükte dört kazı yapılmış, ancak bu kazıların ilk üçünde tablet bulunamamıştır. Tabletlerin bulunması ise bölgedeki köylülerden gelen ihbarları değerlendiren ve höyügün eteğindeki tarlaya odaklanan B. Hrozny'nin gerçekleştirdiği dördüncü kazıda bin kadar tabletin ortaya çıkarılmasıyla gerçekleşmiştir. Böylece Asurlu tüccarların ikamet ettiği Kaniš Kārum'u keşfedilmiştir. ${ }^{2}$ Hrozny'nin ortaya çıkardığı bu tabletler Asurologlar tarafinda yayınlanmış ve bu araştırmalarla Kültepe'deki belgelerin tüccarlara ait arşivler olduğu ve oradaki evlerde yaşayan insanların ticari ve hukuki prosedürlerini yansıttığı anlaşılmıştır. ${ }^{3}$ Höyükte ilk sistematik kazılar ise Türk Tarih Kurumu ve Eski Eserler Genel Müdürlüğü adına 1948 senesinde Tahsin Özgüç başkanlığında başlanmıştır. ${ }^{4}$ Tahsin Özgüç ilk iki yılda yaptığı kazılarla, Kārum'un dört tabakadan oluştuğunu ve Asurlu tüccarların tabletlerin ortaya çıkarıldığg ikinci tabakada buraya yerleştiklerini ortaya koymuştur. ${ }^{5}$ Ayrıca bu belgelerin tamamının Asurlulara ait olmadığı ve ortaya çıkarılan bazı belgelerin ise Anadolu'nun yerlisi olan tüccarlara ait olduğu anlaşılmıştır. ${ }^{6}$

Bu çalışmada 1949 yılı Kültepe kazılarından ele geçirilen arşive ${ }^{7}$ ait 13 tablet ve bunların bazılarına ait zarflar ele alınacaktır. Belgelerden 12 tanesi borç sözleşmesi, 1 tanesi ise bir hizmetin ücretinin ödenmesiyle ilgilidir. Borç sözleşmelerinin 10 tanesi Asurlular arasında düzenlenmişken 1 tanesi Asurlu tüccarlar ile Kārum kurumu arasında ve 1 tanesi ise Asurlu bir tüccar ile bir Anadolulu arasında düzenlenmiştir. Belgelerden Asurlu tüccarın hem Asurlulara hem de Anadolululara borç verdiği görülmektedir. Lìmum tarihlemelerine bakarak belgelerin MÖ 1917-1836 yılları arasında düzenlendiğini söyleyebiliriz. ${ }^{8}$

Tabletlerde tarihlemelerin Asur geleneğine uygun olarak lìmum (y1l) ve hamuštum (hafta) esasına göre yapıldığı görülmektedir. Tarihleme usullerinde kısa vâdeli borçlar için sadece hafta adı kaydedilirken, uzun vâdeli borçlar için yıl ismi kullanılmıştır. Belgelerde borcun ödeneceği

\footnotetext{
${ }^{1}$ Gojko Barjamovic - Thomas Hertel - Trolle Larsen, Ups and Downs at Kanesh - Observations on Chronology, History and Society in the Old Assyrian Period. Leiden, 2012, s. 57.

${ }^{2}$ Cahit Günbattı, Kültepe Kaniş, Anadolu'da İlk Yazı, İlk Belgeler. Kayseri Büyükşehir Belediyesi Kültür Yayınları, Kayseri 2017, s. 32-33.

${ }^{3}$ Mogens Trolle Larsen, Ancient Kanesh: A Merchant Colony in Bronze Age Anatolia. Cambridge, 2015, s. 22.

${ }^{4}$ Klaas Roelof Veenhof, "Kanesh. An Assyrian Colony in Anatolia", CANE 2, 1995, s. 859.

${ }^{5}$ Günbatt1, age., s. 37.

${ }^{6}$ Veenhof, agm., s. 861

${ }^{7} 1949$ yll kazılarında 839 tablet ele geçirilmiştir. Bkz, Cecile Michel, Old Assyrian Bibliography of Cuneiform Texts, Bullae, Seals and the Results of the Excavations at Assur, Kültepe/Kanis, Acemhöyük, Alishar and Bogazköy. OAAS 1, Leiden: 2003. Bu arşiv Doç. Dr. Hakan Erol tarafindan yayıma hazırlanmaktadır.

${ }^{8}$ Barjamovic vd. 2012: 92-97; Cahit Günbatt1, “An Eponym List (KEL G) from Kültepe”, AoF, 35-1, 2008, ss. 103132; Klaas Roelof Veenhof, The Old Assyrian List of Year Eponyms from Karum Kanish and its Chronological Implications. (TTKY Vl/64), Ankara 2003, s.3-18.
}

\author{
History Studies \\ www.historystudies.net
}


süre çoğunlukla hafta sayısıyla ifade edilmiştir. Kimi zaman da tanrılar adına düzenlenen bayramlar borcun ödeneceği tarih olarak kaydedilmiștir. Bununla birlikte bazı zirai tabirler de borcun vadesini belirtmek üzere kullanılmıştır. ${ }^{9}$ Ayrıca Kültepe'den keşfedilen lìmum listeleri tabletlerin kronolojik olarak tarihlemesini mümkün kılmakta ve böylece koloni devrinin kronolojisi ortaya koyulabilmektedir. ${ }^{10} 1949$ senesine ait yayımlanan diğer belgelerdeki ${ }^{11}$ lìmum isimleri olarak karşımıza çıkan Šu-Dadan'ın oğlu Abia ${ }^{12}$ (Kt b/k 226: 7) Aššur-Damiq (Kt b/k 38b: 22) $)^{13}$, İphurum ${ }^{14}$ (Kt b/k 190: 18-19) Elāli ${ }^{15}$ (Kt b/k 114: 14), Kūbiya ${ }^{16}$ (Kt b/k 720: 7) Salliya $^{17}$ (Kt b/k 672b: 16), bizim yayınladığımız belgelerden geçen Šu-Ǐštar ${ }^{18}$ ve Dan-Ea ${ }^{19}$ lìmumlarına bakıldığında belgelerin büyük oranda Asur kralı I. Sargon (MÖ 1917- 1878), II. Puzur-Aššur (MÖ 1877-1870) ve Naram-Sin (MÖ 1869-1836+x) dönemlerine tarihlendikleri sonucu ortaya çıkmaktadır. ${ }^{20}$ Belgelerde tarihleme olarak sadece limmum (y1l) ve hamuštum adları kullanılmamış, bazı zirai tabirler de borcun vadesini belirtmek üzere kullanılmıştır. ${ }^{21}$

\title{
1. Kt b/k 209
}

\section{Tablet (3.1x3.3x1.3)}

İki Asurlu arasında yapılmış bir borç sözleşmesidir. Hamuštum haftası belirtilerek düzenlenen belgede \% 30 faiz ödeneceği ifade edilmiştir. Buna ek olarak borç için bir kefil tayin edilerek ödeme garanti altına alınmıştır.

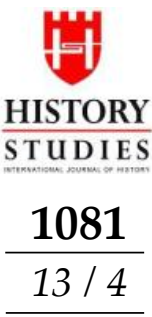

\footnotetext{
${ }^{9}$ Sebahattin Bayram, "Kültepe Tabletlerinde Geçen Yeni bir Vâde İfâdesi ve Çıkan Neticeler”, X. Türk Tarih Kongresi, II, 1990, Ankara, s. 454-455; Salih Çeçen ve L. Gürkan Gökçek, "Kültepe Tabletlerinde Yerli Tarihleme Usulleri”, Studies in Honor of Hayat Erkanal Cultural Reflections, 2006, s. 218-219.

${ }^{10}$ Günbatt1, age., 2017, s. 37.

${ }^{11}$ Salih Çeçen - Faruk Akyüz, "1949 Y1lı (Kt. b/k) Kültepe Kazısından Aššur-țab’a Ait Bir Grup Borç Mukavelesi”, Akademik Tarih ve Düşünce Dergisi, 2018, 5 (17 Ek Özel Say1), ss. 1-28; Salih Çeçen ve Koray Toptaş, 2019. "1949 Yılı (Kt. bk) Kültepe Kazısından Karriya'ya Ait Bir Grup Borç Sözleşmesi”, Tarihin İzinde Bir Ömür: Prof. Dr. Nuri Yavuz'a Armağan, Ankara, ss. 312-326; Salih Çeçen ve Faruk Akyüz "Kültepe'den Bazı Ticari Belgeler ve Bunların Değerlendirilmesi". ArAn, 13/2, 2019, ss. 101-122.

12 KEL A 75; REL 76.

${ }^{13}$ KEL A 83; REL 84.

${ }^{14}$ KEL A 66; REL 67.

${ }^{15}$ KEL A 91; REL 92.

${ }^{16}$ KEL A 96; REL 97.

17 KEL A 76; REL 77.

18 İkūnum'un oğlu Šu-İštar līmum’u ile eşleştirilmektedir. Bkz. Veenhof, age., 2003, s. 25; Barjamovic vd., age., s. 120.

${ }^{19}$ KEL G 25; REL 135.

${ }^{20}$ Barjamovic vd., age., s. 91-95.

${ }^{21}$ Sebahattin Bayram, "Kültepe Tabletlerinde Geçen Yeni bir Vâde İfâdesi ve Çıkan Neticeler", X. Türk Tarih Kongresi, II, 1990, Ankara, s. 454-455; Salih Çeçen ve L. Gürkan Gökçek, "Kültepe Tabletlerinde Yerli Tarihleme Usulleri”, Studies in Honor of Hayat Erkanal Cultural Reflections, 2006, s. 218-219.
}

\author{
History Studies \\ www.historystudies.net
}




$\begin{aligned} \text { Öy. } 1 & \text { 2/3 ma-na } 5 \text { GÍN } \\ 2 & \text { KÙ.BABBAR } i \text {-șé-er } \\ 3 & \text { DİNGİR-na-da } \\ 4 & \text { DİNGİR-A-šur } i \text {-šu } \\ 5 & \text { iš-tù ha-mu-uš-tim } \\ 6 & \text { ša DUMU Ba-na-ga }\end{aligned}$

Ak. $7 \quad \grave{u} A-g u_{5}-a$

Ay. $8 \quad 1 \frac{1}{2}$ GÍN.TA

$9 \quad i$-na İTİ.KAM

10 a-ma-na-im

$11 u$ úṣa-áb

12 Kà-șu-ra-nu-um

13 qá-ta-tum

14 İGİ En-na-Sú-en

Ük. 15 İGİ $D a-d i-a$

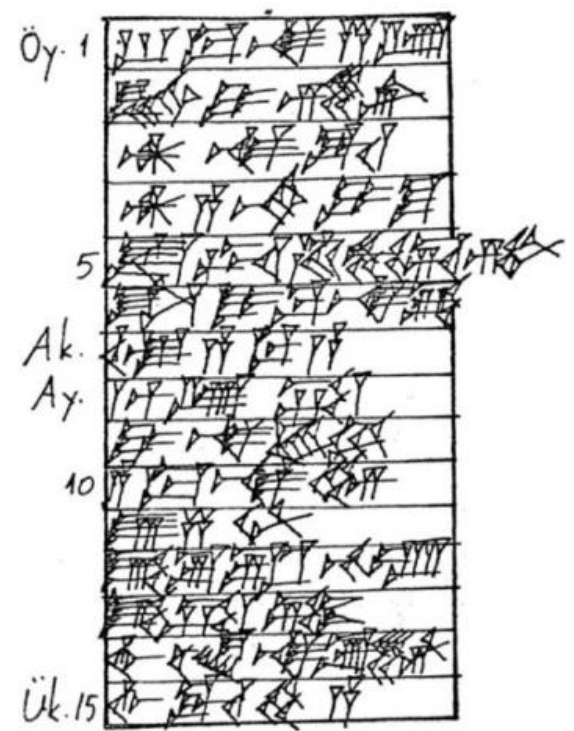

HISTORY STUDIES 1082

1-4 İlî-Aššur'un İlī-nādā'da $2 \frac{2}{3}$ mina 5 šeqel gümüşü vardır. ${ }^{5-7}$ Agua ve Banaga'nın oğlunun hamuštum'undan itibaren ${ }^{8-11}$ bir minaya $1 \frac{1}{2}$ šeqel faizi ilave edecektir. ${ }^{12-13}$ Kefil: Kașșuranum. ${ }^{14-15}$ Şahitler Enna-Suen, Dadia

St. 6: J. Lewy hamuštum'un 50 günlük bir süreyi ifade etmek için kullanıldığını söylemektedir. ${ }^{22}$ Ancak, metinlerde 100 hamuštum ifadesinin dahi geçtiği örnekler mevcuttur. Bu hesapla 100 hamuštum 21 yıl etmektedir ki, bu tarih bir borcun geri alınması için oldukça uzun bir süredir. Bu bilgiden hareketle 1 hamuštum'un 5 ya da 7 günlük bir süre zarfını ifade ettiğini söylemek daha doğru olacaktır. K. R. Veenhof da hamuštum için 7 günlük süreyi ifade ettiğini vurgulamıştır. ${ }^{23}$

St. 7: Agua: Bu şahıs ismi (-a) ile sonlanan yerli isimler grubu ile mukayese edilmeli ve o grup içine dâhil edilmelidir. ${ }^{24}$

St. 12: Kașṣuranum ismi "kașāru" fiilinden yapılmış bir isimdir. Kașṣarum "depo memuru" (AHw, s. 458'de) anlamında verilmiş olan kelime ile karşılaştırılabilir. Bu isimin, kașṣārum kelimesinin sonuna (-anum) çoğul eki getirilerek yapılmış bir isim olduğu fikrindeyiz.

\footnotetext{
${ }^{22}$ Hildegard Lewy and Julius Lewy, The Origin Of The Week And The Oldest West Asiatic Calendar. Hebrew Union College Annual (HUCA), Vol. 17, 1942-43, s. 47.

${ }^{23}$ Klaas Roelof Veenhof, "The Old Assyrian Hamuštum Period: A seven-day week”, JEOL 34 (Jaarbericht van het Vooaziatisch-Egyptisch Genootschap Ex Oriente Lux), 1996, ss. 5-26.

${ }^{24}$ Emin Bilgiç, Kapadokya Metinlerinde Geçen Yerli Apellatifler ve Bunların Eski Anadolu Dilleri İçerisindeki Yeri. Ankara: Türk Tarih Kurumu Basımevi, 1953, s. 5.
} 


\section{Kt b/k 518}

\section{Tablet (3.5x3.7xl.8)}

İki Asurlu arasında yapılmış bir borç sözleşmesidir. Borcun veriliş târihi hamuštum ve lìmum ismi zikredilerek kaydedilmiştir.

\begin{tabular}{|c|c|}
\hline Öу. 1 & 922 1/2 40 GÍN \\
\hline 2 & KÙ.BABBAR i-șé-er \\
\hline 3 & Ṭá-bii $-A-\check{s} u r$ \\
\hline 4 & $A-\check{s} u r-i-d i \quad i-s ̌ u$ \\
\hline 5 & $i \check{s}-t \grave{u} h a-m u-u s ̌-t i m$ \\
\hline 6 & $\check{s} a \dot{U}-s u ́ u-u r-\check{s} a-\dot{I s} t a r$ \\
\hline 7 & İTİ.1.KAM Qá-ra-a-tim \\
\hline 8 & li-mu-um \\
\hline
\end{tabular}

Ak. 9 I-na-Sú-en 6

Ay. $10 \quad 1 / 3$ GÍN.TA

11 sí-ib-tám

$12 u$ úsa-áb

13 İGI $\breve{S} u-A-s ̌ u r$

14 İGİ $U-z u-a$

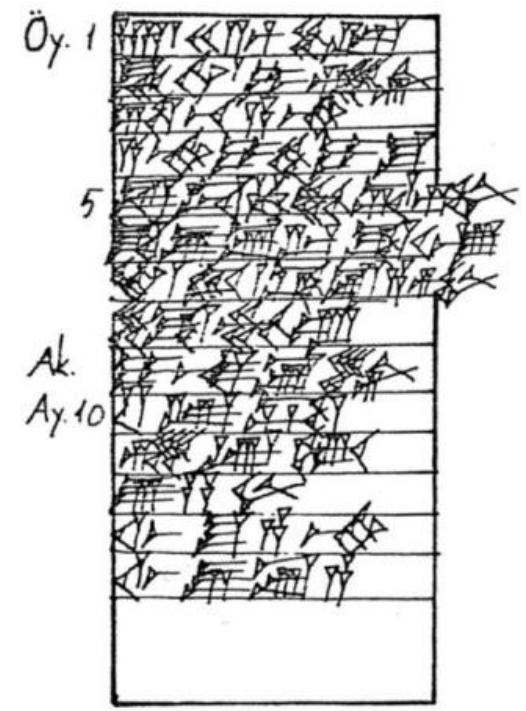

${ }^{1-4}$ Aššur-idī’nin, Țābi-Aššur'da 9 (šeqel) 22 1⁄2 (šeqel) (ve) 40 šeqel gümüşü vardır. 5-6 Ușurša-İštar'ın hamuštum'undan itibaren, ${ }^{7}$ Qarrātum ay1, ${ }^{8-9}$ Enna-Suen' in līmum'u ${ }^{10-121 / 5}$ šeqel faizi ilâve edecek. ${ }^{13-14}$ Şahitler: Šu-Aššur, Uzua.

St. 1: Rakamların, kâtip tarafından bu şekilde yazılması bizce normal olmayan bir duruma işaret etmektedir. Burada kâtip rakamları yanlış kaydetmiş olabilir, bunun yanında üç ayrı borç miktarının da mevzu bahis olması seçenekler arasında değerlendirilmelidir.

St. 9: Enna-Suen lìmum adı, Kültepe II. tabakada 5 farklı şekilde geçmektedir. ${ }^{25}$ Bu da sadece isme bakarak buradan tam bir tarihleme yapmaya engel olmaktadır. KEL $\mathrm{A}^{26}$ 'da 106. ve 114. $\mathrm{KEL} \mathrm{G}^{27}$ de 26. ve 28. sırada geçmektedir. Enna-Suen babasının ismiyle birlikte geçmemesi sebebiyle kesin bir eşleştirme yapamıyoruz. Bunun yanında arşivdeki diğer tabletlerin tarihlemeleri yol gösterici olabilir.

St. 14: Uzua (-a) ile sonlanan isimlere yerli bir şahıs ismidir. ${ }^{28}$

\footnotetext{
${ }^{25}$ Günbatt1, agm., 2008, s. 113 ve 120.

${ }^{26}$ Veenhof, age., 2003, s. 9.

${ }^{27}$ Günbatt1, agm., 2008, s. 111 ve 120.

${ }^{28}$ Bilgiç, age., 1953, s. 5.
} 


\section{Kt b/k 196}

\section{Tablet (4.6x4.6x1.7)}

Asurlular arasında yapılmıs bir borç sözleşmesidir. Borcun veriliș tarihi hamuštum ve līmum zikredilerek belirtilmiștir. Ödeme günü 12 hamuštum'luk bir zamandır. Paranın ödenmesini garanti altına almak amaciyla borcun sağ ve meşru olanların başına bağlanmış olduğu ibaresi sözleşmeye eklenmiştir. Borcun gününde ödenmemesi durumunda \%30 faiz uygulanacağ 1 belirtilmiştir.

\begin{tabular}{|c|c|}
\hline Ӧу. 1 & $2 / 3 m a-n a$ \\
\hline 2 & KÙ.BABBAR șa-ru-pá-am \\
\hline 3 & $i$-șé-er A-šùr-be-el-a-wa-tim \\
\hline 4 & ù En-nam-A-šùr \\
\hline 5 & $\grave{I}$-lí-a-lúm i-šu \\
\hline 6 & $i \check{s}-t \grave{u} h a-m u-u \check{s}$-tim \\
\hline 7 & $\check{s} a \mathrm{Na}-\mathrm{ra}-a m-\mathrm{Zu}$ \\
\hline 8 & ù Ha-na-nim a-na \\
\hline 9 & 12 ha-am-ša-tim \\
\hline 10 & $i-\check{a} a-q u \dot{u}-l u \check{s} u-m a$ \\
\hline Ak. 11 & $i-n a u_{4}-m i \grave{s} \breve{s} u-n u$ \\
\hline 12 & $m a-a l-\dot{u}$-tim \\
\hline 13 & lá $i s ̌-q u^{*}-l u$ a-na \\
\hline 14 & 1 ma-na-im 1¹/2 GíN.TA \\
\hline 15 & İTİ.KAM șí-ib-tám \\
\hline 16 & $\dot{u}$-șú-bu \\
\hline 17 & İGİ En-nam-ma-nim \\
\hline 18 & İGİ Bu-kà-nim KÙ.BABBAF \\
\hline 19 & i-na qá-qá-ad \\
\hline 20 & $\check{s} a-a l-m i-s ̌ u-n u$ \\
\hline 21 & $r a-k i-i s$ \\
\hline
\end{tabular}

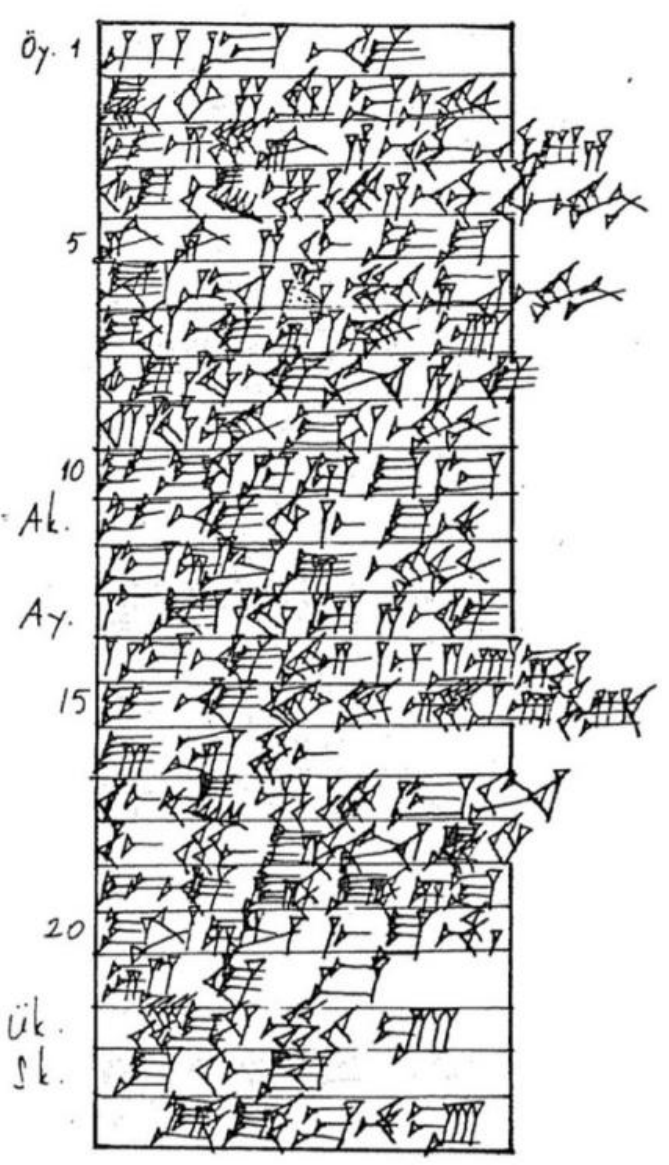

Ük. 22 li-mu-um

Sk. $23 \quad \check{S} u$-Ǐstar

$24 k \grave{a}-k \grave{a}-b a-n u-u m$

1-5 İlī-ālum'un Ennam-Aššur ve Aššur-bēl-awātim' de $2 / 3$ mina arıtılmış gümüşü vardır. ${ }^{6-8}$ Hananu ve Naram-Zu'nun hamuštum'undan itibaren, ${ }^{8-10} 12$ hamuštum'a kadar ödeyecekler. Eğer $\quad{ }^{11-12}$ borcun ödenmesi lazım gelen günde ödemezlerse, ${ }^{14-16}$ ayda 1 minaya $1 \frac{1}{1 / 2}$ šeqel (faizi) ilave edecekler. ${ }^{17-18 a}$ Şahitler: Ennam-Anum, Bukanum ${ }^{18 b-21}$ Para sağ olanların başına bağlanmıştır. ${ }^{22-24}$ kakkabānum Šu-İštar'ın lìmum'u.

St. 11-12: i-na u u-mì-šu-nu ma-al-ú-tim: "dolu gününde" mânası olup (AHw, 597), "borcun ödenmesi lâzım gelen günü dolduğunda" anlamında alıyoruz.

St. 22-24: līmum Šu-İštar "kakkabânum" kelimesi ile birlikte verilmiștir. Bu kelime için "yıldız, yıldız gibi” (AHw, 421) manasına gelmektedir ve bir takma ad olduğu düşünülmektedir.

\footnotetext{
* Met: -ha
} 
Burada yer alan Šu-İštar līmum'u KEl A'da 74 sıradaki REL'de ise 75. sırada yer alan İkūnum 'un oğlu Šu-İštar lìmum'u ile eşleştirilmektedir. ${ }^{29}$ Bu durumda belgenin Asur kralı Sargon döneminde, yaklaşık MÖ 1888 yılında düzenlenmiştir. ${ }^{30}$

\section{Kt b/k 175}

\section{Tablet (4.8x5.1x1.9)}

Asurlular arasında yapılmış bir borç sözleşmesidir. Paranın veriliş tarihi ay ve yıl adı belirtilerek kaydedilmiştir. Paranın 15 hamuštum'a kadar ödenmesi, ödenmemesi hâlinde \% 40 faiz uygulanacağı zikredilmiştir. Ayrıca borca ortak olan diğer şahısın ölmesi sebebiyle onun üzerine düşen borç ve fâizinin de hayatta olan ortağı tarafından ödeneceği kaydedilmiştir.

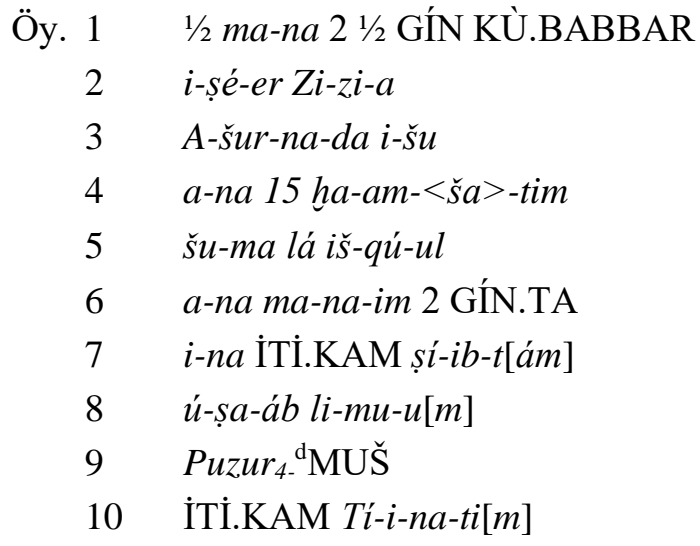

Ak. $11 \quad \check{s} u$-ma i-na țup-pí-im

Ay. 12 ša hu-bu-ul

13 Zi-zi-a ù Lá-qé-pì-im

14 KÙ.BABBAR i-na qá-qá-ad

15 ša-al-mì-šu-nu

16 KÙ.BABBAR $r a-k i$-is KÙ.BABBAR

17 ù și-ba-sù ša Lá-qé-pì-im

18 Zi-zi-a $i$-ša-qal

19 İĠ̀ Ha-na-ri-im

20 DUMU $\dot{I}-z i-z a-a m-\grave{-}-l i$

Ük. 21 İGİ $A-\check{s} u r-i-d i$

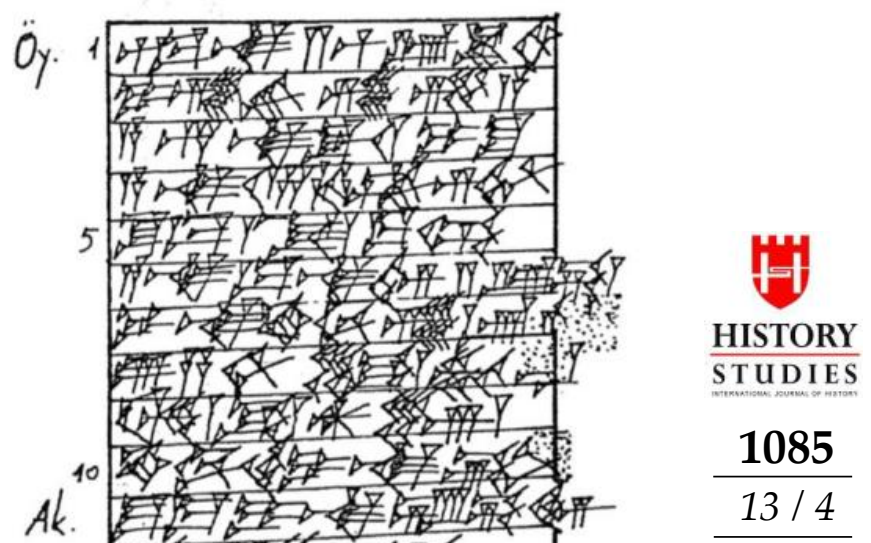

22 DUMU Mu-mu-lá-nim

${ }^{1-3}$ Aššur-nādā'nın Zizia' da 1/2 mina $21 / 2$ šeqel gümüşü vardır. ${ }^{4-7} 15$ hamuštum'a (kadar) eğer ödemezse, bir ayda 1 minaya 2 šeqel faizi ilâve edecek. ${ }^{8-9}$ Puzur-Nirah'ın lìmum'u ${ }^{10}$ Tìnati ay1. ${ }^{11-19}$ Eğer, Zizia ve Lā-qēpum'un borç senedindeki gümüş, onların sağ olanlarının başına bağlanmışsa, Lā-qēpum'un gümüşünü ve faizini (de) Zizia ödeyecek. ${ }^{19-20}$ Şahitler: İzizamilī’nin oğlu Hanārum, Mumulānum'un oğlu Aššur-idī.

St. 8-9: Puzur-Nirah līmum ismi olarak KEL A'da Puzur-Suen'in oğlu olarak 84. sirada geçmektedir. KEL G'de ise 57. ve 124. sırada geçmektir. Puzur-Nirah isminin 3 farklı seneye

\footnotetext{
${ }^{29}$ Veenhof, age., 2003, s. 25; Barjamovic vd., age., s. 120.

${ }^{30}$ Barjamovic vd., age., s. 93.
} 
isim olarak verilmesi ve bizim belgemizde de baba adıyla birlikte verilmemesi belgeyi kesin olarak tarihlememize engel olmaktadır. Ancak arşivdeki diğer belgelerden yola çıkarak KEL A'da Puzur-Suen'in oğlu olarak 84. sirada geçen Puzur-Nirah ile aynı olması yüksek bir olasılıktır. Bu durumda belgenin Asur Kralı Sargon döneminde MÖ 1888 y1lına tarihlenmesi gerekmektedir (REL 85).

St. 10: warah Tinatim: Eski Asur Dönemi'nde ay adı olarak kullanılmaktadır. İncir ağacı anlamına gelen "tittu" kelimesinden türetilmiştir (CAD T 435). Bu bilgilerden hareketle bu ayın "incirlerin olgunlaştığı ay" anlamına geldiği düşünülebilir. Burada zirai bir tabirin vade için kullanıldı̆̆ı görülmektedir. ${ }^{31}$

\title{
5. Kt b/k 218
}

\section{Tablet (3.7x4.2x1.9)}

İki Asurlu arasında yapılmış bir borç sözleşmesidir. Borcun ödeneceği zaman hamuštum esasına göre tayin edilmiş̧ir.

\begin{tabular}{|c|c|c|}
\hline & Öy. 1 & 1/2 ma-na 5 GÍN KÙ.BABBAR \\
\hline & 2 & șa-ru-pá-am i-șé-er \\
\hline HISTORY & 3 & $A-\check{s} u r$-DUG DUMU Ù-șa-ri-a \\
\hline STUDIES & 4 & Illis-ba-ni DUMU Puzur ${ }_{4}-A-\check{s} u r$ \\
\hline 1086 & 5 & $i-\check{s} u \check{s} a A-\check{s} u r-i-m i ̀-t i$ \\
\hline $13 /$ & 6 & $\grave{u} A$-šur-ta-ak-lá-ak \\
\hline
\end{tabular}

Ak. 7 ha-mu-uš-tim ša-pá-tám

Ay. $8 \quad i$-li-kà-ma ǐs-tù

9 ša-pá-tim KÙ.BABBAR

10 a și-ib-tim ki-ma a-wa-tim!

$11 k \grave{a}$-[ri]-im i-lá-ak

12 İGI X-ba-a Šu-be-lim

13 İGİ İ-da-a DUMU díšKUR-ba-ni

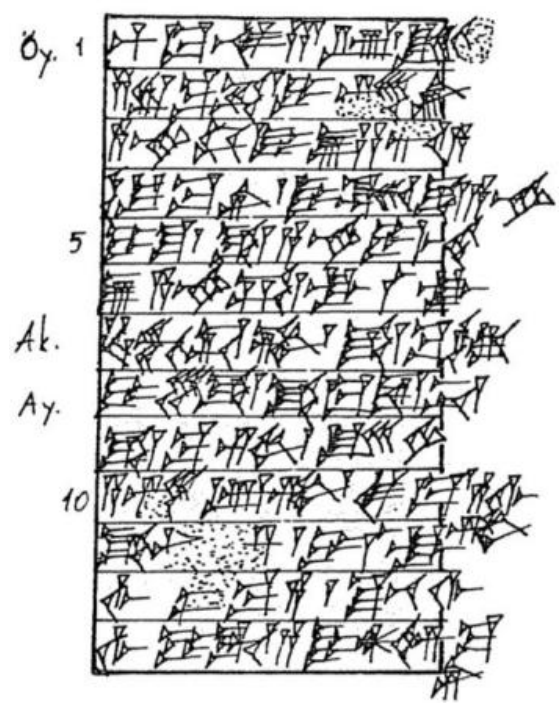

${ }^{1-5}$ Puzur-Aššur'un oğlu İlī-bāni'nin, Ușaria'nın oğlu Aššur-țāb'da 1/2 mina 5 šeqel arıtılmış gümüşü vardır. ${ }^{5-11}$ Aššur-imittī ve Aššur-taklāk'ın hamuštum'undan itibaren (bir) šapattu geçti ve šapattu'dan itibaren gümüş Kārum'un hükmü gereğince faize gidecek. ${ }^{12-13}$ Şahitler: X-ba (ve) Šu-bēlim ve Adad-bāni'nin oğlu İdaya

St. 7: šapattu: "ayın 15. günü; dolunay" manalarına gelmektedir (AHw, 1172). Fakat K. Balkan, bu kelimenin karşılığı hakkında örnekler sunarak, yalnız 15. gün anlamında kullanılacağını iddia ederek 15 günlük bir zaman olarak kullanılması gerekeceğini belirtir ${ }^{32}$. Metinimizde geçen "šapattu" kelimesini 15. gün olarak aldığımızda tercüme yapmamız zorlaşmakta ve bizim metin yerimize uymamaktadır. Fakat 15 günlük bir müddet kabul edip kullandığımızda daha mantıklı ve olumlu tercüme yapma şansı oluşmaktadır. Bu sebeple "šapattu" kelimesinin 15 günlük bir mühleti gösterdiğini ve metinimizin buna yeni bir delil olduğunu söyleyebiliriz.

\footnotetext{
${ }^{31}$ Bayram, agm., 1990, s. 454-455; Çeçen - Gökçek, agm., s. 218-219.

${ }^{32}$ Kemal Balkan, "The Old Assyrian Week", Studies in Honor of Benno Landsberger on His Seventy-Fifth Birthday, (University of Chicago.Oriental Institute.Assyriological studies;no.16) 1965, s. 164.
}

\author{
History Studies \\ www.historystudies.net
}




\section{6a. Kt b/k 54a}

\section{Zarf (5x5.5xl.5)}

Bir Asurlu ve bir yerli şahıs arasında yapılmış bir borç sözleşmesinin zarfıdır.

Öy. $\quad$ Silindir mühür A

$\begin{array}{ll}1 & \text { KİŠİB } D u-d u-p i-a-l a ́ \\ 2 & {[\ldots] \text { KİŠİB } D u \text {-du-na }} \\ 3 & \text { KİŠİB } Z u-u[r]-d i \text {-ni } \\ & \text { Silindir mühür B }\end{array}$

4 [KİŠİ] Ni-ak-na

$5 \quad \check{s} a 12$ GÍN KÙ.BABBAR

Ay. $\quad$ Silindir mühür $\mathrm{C}$

$6 \quad i$-șé-er Du-du-na

7 ša Ha-tim Pí-lá-ah-ištar

$8 \quad i$-šu a-na qi-tí-ip

9 kà-ra-nim i-ša-qal

Silindir mühür D

Ük. Silindir mühür E

Sk. Silindir mühür E

${ }^{1}$ Dudupiala'nın mühürü, ${ }^{2}[\ldots]$ Duduna'nın mühürü ${ }^{3}$ Zur-dīni'nin mührü ${ }^{4}$ Niakna'nın mührü. ${ }^{5-9}$ Hattumlu Duduna'nın Pilah-İštar'a 12 šeqel gümüş borcu vardır. Bağ bozumuna kadar ödeyecek.

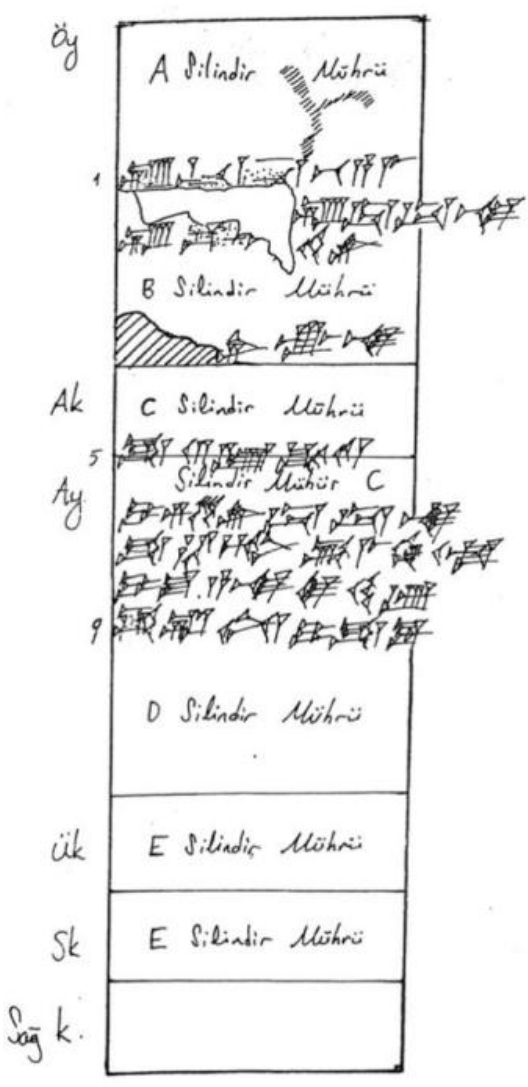

\section{6b. Kt b/k 54b}

Tablet (3.7x4.3x1.6)

Bir Asurlu ve bir yerli şahıs arasında yapılmış bir borç sözleşmesidir. Paranın ziraî bir tâbir olan bağ bozumuna kadar ödenmesi istenmektedir.

$\begin{array}{rl}\text { Öy. } 1 & \text { 12 GÍN KÙ.BABBAR } \\ 2 & i \text {-șé-er } \\ 3 & \text { Du-du-na } \\ 4 & \text { Pí-lá-ah-íš́tar } i \text {-šu-ú } \\ 5 & a-n a q i \text {-tí-ip } \\ 6 & k \grave{a}-r a-n i m \\ 7 & i \text {-ša-qal }\end{array}$
Ak. 8 İGİ Zu-ur-di-ni
Ay. 9 İGİ $D u-d u-p \grave{i}-a-l a ́$
10 İGİ $N i-a k-n a$

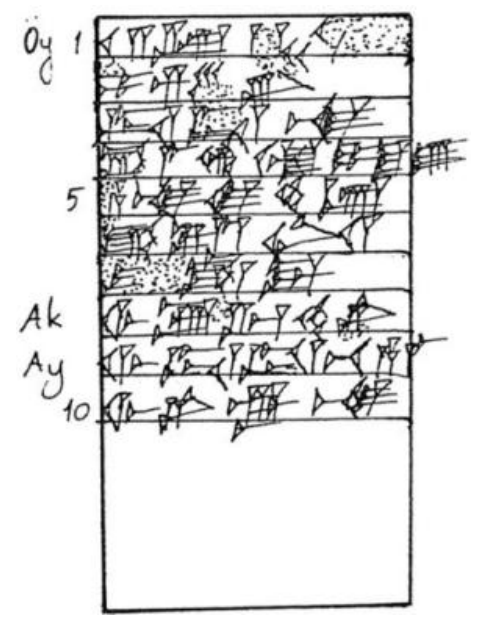


${ }^{1-4}$ Pilah-İštar'1n Duduna'da 12 šeqel gümüşü vardır. ${ }^{5-7}$ Bağ bozumuna (kadar) ödeyecek. ${ }^{8-}$ ${ }^{10}$ Şahitler: Zur-dīni, Dudupiala ve Niakna.

St. 3: Duduna yerli bir şahıs adıdır. Tabletin zarfında Hattumlu Duduna şeklinde geçmektedir. Buradan da bu yerli şahısın Hattumlu bir yerli olduğu anlaşılmaktadır.

St. 5-6: ana qitip karānim: "üzüm koparma zamanına (kadar); bağ bozumuna (kadar)" manalarına gelmektedir (AHw, 92). Burada zirai bir tabir yine vade için kullanılmıştır. ${ }^{33}$

St. 10: Niakna, sonu "-na" ile sonlanan yerli bir şahıs ismidir.

\section{Kt b/k 169}

\section{Tablet (5-2x4.9x2)}

Asurlu tüccarın ișlerinin yapılmasına yardım eden adamına bu hizmetinden dolayı,"be'âlum" parası olarak 5 mina arıtılmış gümüş verdiği belirtilmektedir. İki ay geçtikten sonra ticaret için giden kervanın ilk tasarrufundan bu bahsedilen miktarın ödeneceği kayıtlı bulunmaktadır.
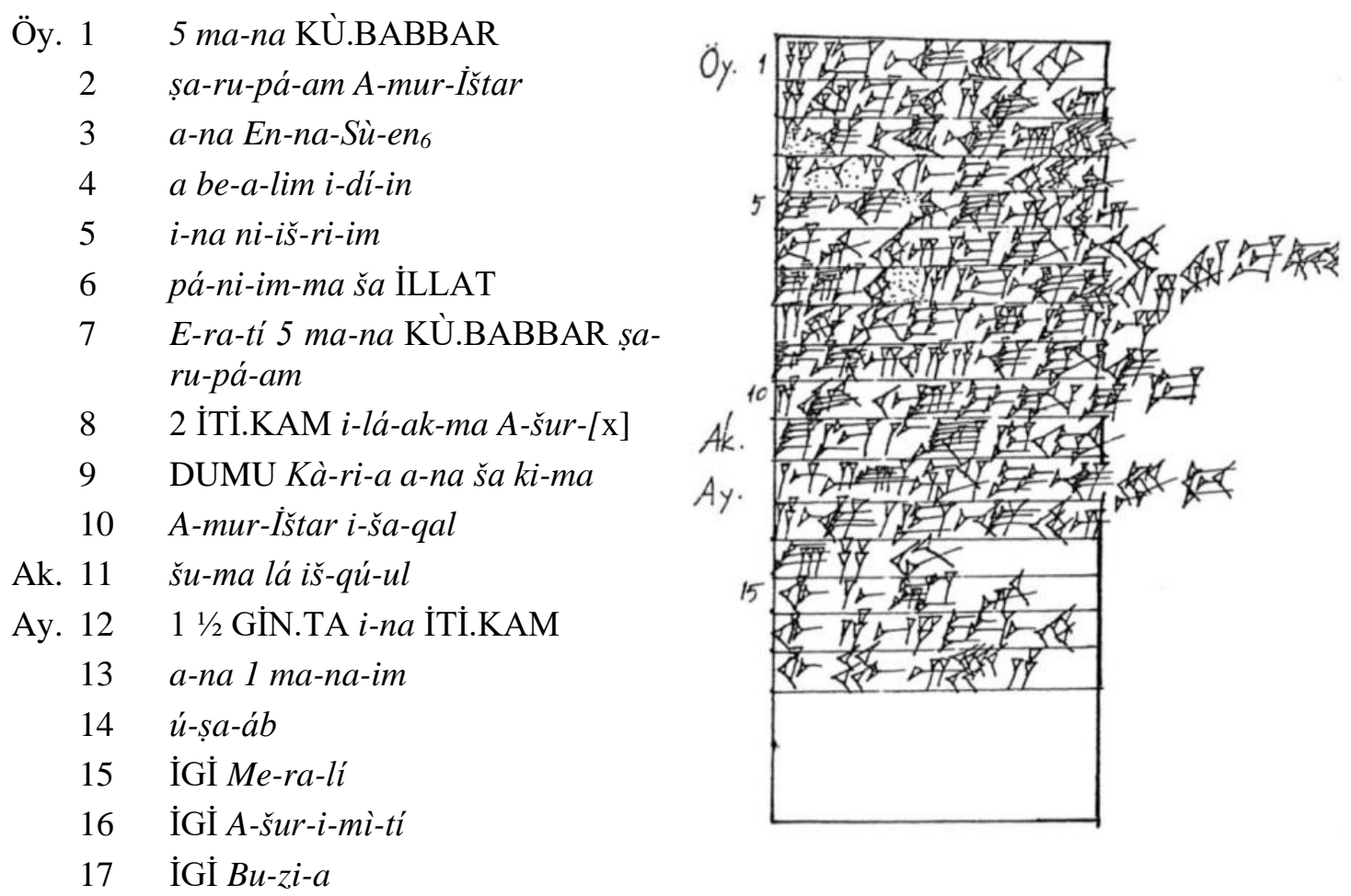

${ }^{1-4}$ Amur-İ̌star 5 mina arıtılmış gümüşü Enna-Suen'e be'ālum (tasarrufu) için verdi. ${ }^{5-11} 5$ mina gümüșü Erati'nin kervanının ilk tasarrufundan 2 ay geçecek ve Karriya'nın oğlu Aššur$\langle\mathrm{x}\rangle$, Amur-Ǐštar'ın vekiline ödeyecek. Eğer ödemezse ${ }^{12-14}$ ayda 1 minaya 1 1/2 šeqel (faiz) ilave edecek. ${ }^{16-17}$ Şahitler: Merali, Aššur-imittī, Buzia.

\footnotetext{
${ }^{33}$ Bayram, agm., 1990, s. 454-455; Çeçen - Gökçek, agm., s. 218-219.
} 


\section{Kt b/k 83}

\section{Tablet (4.1x3.9x1.5)}

İki Asurlu arasında yapılmış bir borç sözleșmesidir. Borcun veriliș tarihi hamuštum adı belirtilerek kaydedilmiştir. Esas borcun ödeme dönemi 13 aylık bir müddettir. Metinde esas borç miktarı kadar bir ikinci ödeme daha vardır ki, biz bu fazladan ödemenin fiktif borç uygulamasına denk geldiğini zannediyoruz.

\begin{tabular}{|c|c|}
\hline Ӧу. 1 & 1/3 ma-na 5 GÍN KÙ.BABBAR \\
\hline 2 & șa-ru-pá-am i-ṣé-er \\
\hline 3 & Puzur $_{4}$-İštar DUMU A-šùr-ma-lik \\
\hline 4 & Puzur $_{4}-\dot{I}_{\text {Štar }} i-\check{s} u$ \\
\hline 5 & $i \check{s}$-tù ha-mu-uš-tim \\
\hline 6 & ša A-li-li ù İ-dí-A-šùr \\
\hline 7 & $a-n a 13$ İTİ.KAM $i$-ša-qal \\
\hline 8 & šu-ma lá iš-qúl ki-ma \\
\hline 9 & $a$-wa-at kà-ri-im \\
\hline 10 & șí-ib-tám ú-ṣa-áb \\
\hline Ak. 11 & ša-ni-tám \\
\hline Ay. 12 & ma-áš-qá-al-tám \\
\hline 13 & 1/33 ma-na 5 GÍN KÙ.BABBAR \\
\hline 14 & $s ̣ a-r u-p a ́-a m a-n a$ \\
\hline 15 & 13 İTİ.KAM h̆a-am-ša-tim \\
\hline 16 & $i$-ša-qal šu-ma lá iš-qúl \\
\hline 17 & $k i-m a$ a-wa-at kà-ri-im \\
\hline 18 & $s ̣ i$-ib-tám úu-ṣa-áb \\
\hline 19 & ŠU.NIGIIN $\quad 5 / 6 \quad$ ma-na \\
\hline & KÙ.BABBAR șa-ru-pu-um \\
\hline 20 & İĠं $A$-ta-tí- $a$ \\
\hline 21 & İGI $A$-šùr $r-b a-n i$ \\
\hline 22 & İGİ Puzur $4-i-l i$ \\
\hline
\end{tabular}

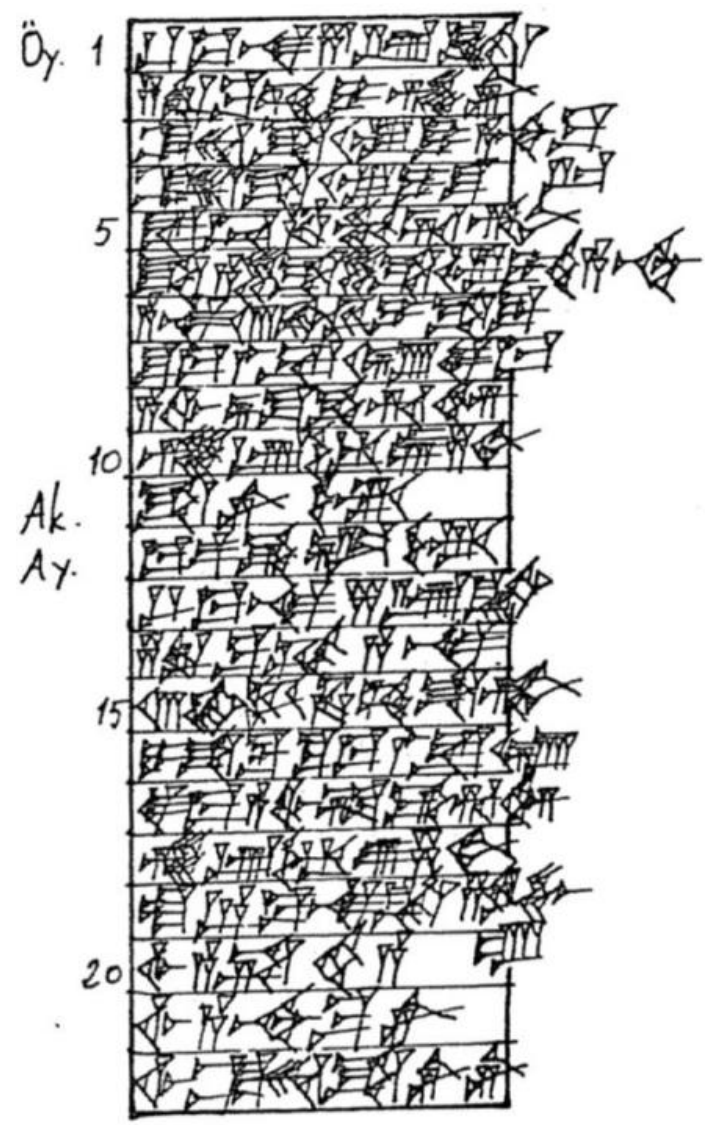

${ }^{1-4}$ Puzur-İ̌star' 1 Aššur-malik' in oğlu Puzur-Ǐštar'da $1 \frac{1}{3}$ mina 5 šeqel arıtılmıș gümüșü vardır. ${ }^{5-7}$ Alili ve İdī-Aššur'un hamuštum'undan itibaren 13 aya (kadar) ödeyecek. ${ }^{8-10}$ Eğer ödemezse Kārum'un hükmü gereğince faizi ilave edecek. ${ }^{11-14} 1 / 3$ mina arıtılmış gümüş (miktarındaki) ikinci ödemeyi, ${ }^{15-18} 13$ aya (kadar) ödeyecek. Eğer ödemezse, Kārum'un hükmü gereğince faizi ilâve edecek. ${ }^{19}$ Toplam $1 \%$ mina arıtılmış gümüştür. ${ }^{20-22}$ Şahitler: Atatia, Aššur-bāni, Puzur-ilī.

St. 11-12: šanitum mašqaltum: "ikinci ödeme" anlamina gelmektedir. mašqaltu = ödeme (AHw, 1164; CAD M 38)

St. 15: Bu satırda kaydedilmiş "hamšatim” kelimesi ilk plânda fazlalık olarak kabul edilebilir. Bu tabirin ilk defa karşımıza çıkması anlamlandırma bakımından bizi şüpheye şevk etmiştir. 


\section{9a. Kt b/k 131a}

Zarf (4x4.5x2)

İki Asurlu arasında yapılmış bir borç sözleşmesinin zarfidır.

\begin{tabular}{|c|c|}
\hline Öy. 1 & KİŠİB $E n-n[a] m-A-\check{s} u r$ \\
\hline 2 & KİŠİB $A-n a-a h-\check{s} u$ \\
\hline & Silindir mühür A \\
\hline 3 & 17 ma-na AN.NA \\
\hline Ak. & Silindir mühür B \\
\hline 4 & $i$-ṣé-er A-na-ah-šu \\
\hline Аy. 5 & $\dot{I}-k u-p \grave{i}-a i-\check{s} u$ \\
\hline 6 & $i$-tù-wa-ri-šu ba-lim \\
\hline 7 & ta-tim ba-lim ni-is-ha-tim \\
\hline 8 & $i$-ša-qal $\stackrel{1}{3} 3 m a-n a \mathrm{KÙ}$ \\
\hline 9 & a-na be-a-lim a-di-šu-um \\
\hline 10 & $i \check{s}$-tù $a-$ lim $^{k i} i-n a$ \\
\hline 11 & $t \grave{u}-w a-r i-s ̌ u$ \\
\hline & Silindir mühür A \\
\hline 12 & 2 İTİ.KAM i-lá-ak-ma \\
\hline Ük. 13 & $i K \grave{a}-n i-i \grave{s}$ \\
\hline 14 & $i-\check{s} a-q a l \stackrel{s}{u} u-m[a]$ \\
\hline 15 & {$[l] a ́$ iš-qú- $[u] l$} \\
\hline 16 & {$[\ldots \ldots]$} \\
\hline 17 & {$[\ldots \ldots]$} \\
\hline & Silindir mühür $\mathrm{C}$ \\
\hline & Silindir mühür D \\
\hline
\end{tabular}

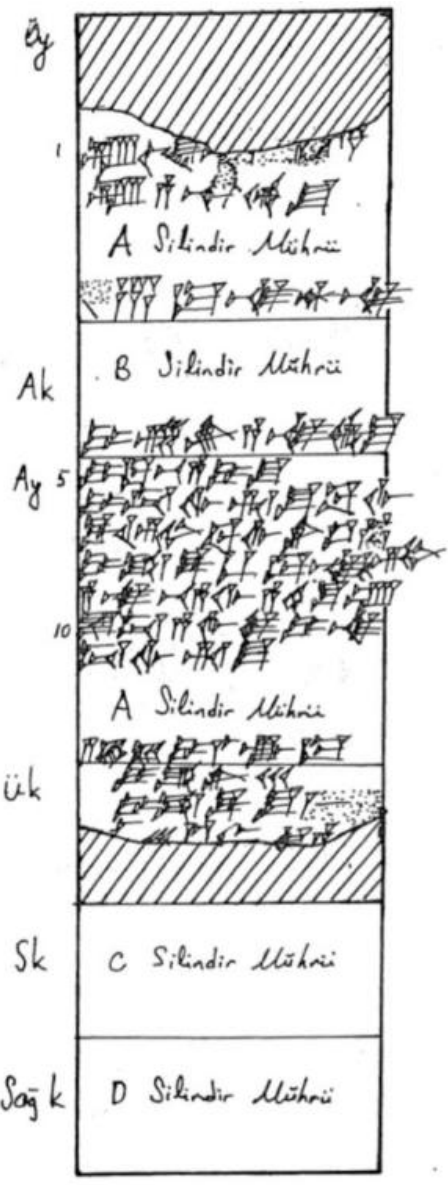

${ }^{1}$ Ennam-Aššur'un mührü, ${ }^{2}$ Anahšu'nun mühürü. ${ }^{3-5}$ İkūppīya'nın Anahšu'da 17 mina kalay1 vardır. ${ }^{6-8}$ Dönüşünde (kalayı) tātumsuz (ve) nishātumsuz ödeyecek. ${ }^{8-9} 1 / 3$ mina gümüşü tasarrufu için ona verdim. ${ }^{10-17}$ İki ay geçip şehirden döndüğünde Kaniš'te (kalay1) ödeyecek. Eğer ödemezse Kārum'un hükmü gereğince faizi ilâve edecek.

\section{9b. Kt b/k 131b}

\section{Tablet $(3.5 \times 3.8 \times 1.5)$}

İki Asurlu arasında yapılmış bir borç sözleşmesidir. Borcun (yâni kalayın) Asur'dan dönüşte Kaniš'te ödenmesi istenmektedir. Bu metinden Asurlu tüccarın kendi malını satması için bir işçi tuttuğu ve ona 17 mina kalayı vererek Anadolu'ya götürmesini istediği ve bu hizmeti için ise ona $1 / 3$ mina gümüşü tasarrufu için verdiğini anlıyoruz. Kalayın "tātum" ve "nishātum" vergileri uygulanmadan verileceği de anlaşılmaktadır. 


\begin{tabular}{|c|c|}
\hline Ӧу. 1 & $17 m a-n a$ AN.NA \\
\hline 2 & $i$-șé-er A-na-ah-šu \\
\hline 3 & $\dot{I}-k u-p \grave{i}-a \dot{i}-\grave{s} u$ \\
\hline 4 & $i-n a$ tù-wa-ri-šu \\
\hline 5 & $i-\check{s} a-q a l$ \\
\hline 6 & ${ }^{1} /{ }_{3} m a-n a$ KÙ.BABBAR \\
\hline 7 & a-na be-a-lim \\
\hline
\end{tabular}

Ak. $8 \quad a-d i$-šu-um

9 iš-tù $a-l i m^{k i}$

Ay. 10 i tù-wa-ri-šu

112 İTİ.KAM $i$-lá-ak-ma

12 i-na Kà-ni-ǐs

$13 i$-ša-qal šu-ma

14 ki-ma a-wa-at

15 kà-ri-im ú-ṣa-áb

16 AN.NA $b a-<l i m>$ ta-tim

17 ba-lim ni-is-ha-tim

Ük. 18 i-da-an

Sk. 19 İGİ $A$-bu-ša-lim

20 İGİ En-na[m]-A-šur

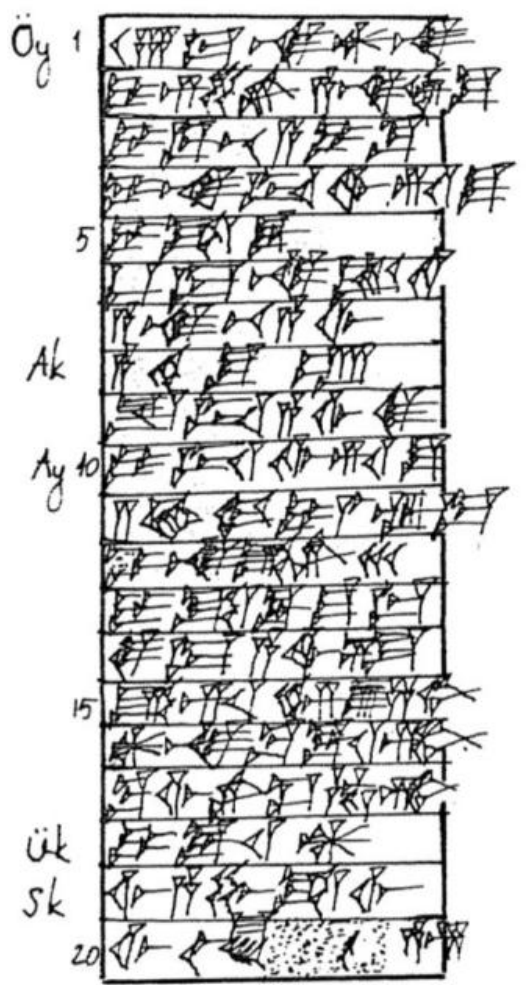

HISTORY

STUDIES

1091

$13 / 4$

1-3 İkūppìya'nın, Anahšu'da 17 mina kalayı vardır. ${ }^{4-5}$ Döndüğünde ödeyecek. ${ }^{6-8}$ 1/3 mina gümüşü ona tasarrufu (be'ālum) için verdim. ${ }^{9-14 a} \mathrm{O}$, şehirden (Asur) döndükten 2 ay sonra, Kaniš’te ödeyecek. ${ }^{14 b-15}$ Eğer (ödemezse) Kārum’un hükmü gereğince (faizi) ilâve edecek. ${ }^{16-18}$ Kalay1, "tātum" (ve) "nishātum" vergileri (uygulanmadan) verecek. ${ }^{19-20}$ Şahitler: Abu-šalim, Ennam-Aššur.

St 7-8: ana be'ālim addišum: "tasarrufu için ona verdim". be'ālum kelimesi "bêlu/be'ālu" (=tasarruf etmek, idâresi altında tutmak) fiilinden yapılmıştır. (CAD B 199; AHw 120).

St. 16: țătum kelimesi "ödeme, ücret” anlamına gelmektedir (CAD Ț 62-63). Muhtemelen bir hizmetin karşıllğında verilmektedir. Kelimenin "transfer ücreti" anlamına gelen taššiātu (CAD T 298) ile birlikte kullanılması malın transfer süreciyle ilgili bir ödemeyi akla getirmektedir. Bu kelimenin țātum, ta'tum ve dâtum telâffuzlarıyla kaydedilmiştir. "tâtum sa harrânim " ifâdesi içerisinde de geçen tâtum, Asur'dan gelen kervanlardan Anadolu'da alınan vergi veya ödeme ya da yol vergisi olarak değerlendirilmektedir. ${ }^{34}$

St. 17: nishātum /nisihtu: Eşya sevk vergisi (CAD N/II 269).

\footnotetext{
${ }^{34}$ Sabahattin Bayram, “Kültepe Tabletlerinde Geçen Vergiler ve Özellikleri”, DTCF-D, Cilt 36, Sayı 1-2, 1993, s. 10.
} 
10a. Kt b/k 135a

Zarf (4.5x5x1.5)
Öy.

Silindir mühür A

1 KİŠỉ $\dot{I}-k u$-nim

2 KİŠỉ $\check{S} u-D a-g a n$

3 ša hu-bu-ul

$4 \quad$ Šu-Da-gan

510 GÍN KÙ.BABBAR

6 șa-ru-pu-um

Ak. $7 \quad i-n u-m i$

Silindir mühür B

Ay. Silindir mühür $\mathrm{C}$

$8 \quad$ a-na $a-$ lim $^{k i}$

$9 \quad a-l u-k u i-s ̌ a-q a l$

10 šu-ma lá iš-qúl

11 ki-ma a-wa-at

Silindir mühür C

$12 k \grave{a}-r i-i m$

Ük.

Silindir mühür C

$13 u ́$ ussa-áb

Sk. Silindir mühür C

Sağ K. Silindir mühür B

${ }^{1}$ İkūnum'un mührü, ${ }^{2}$ Šu-Dagan'ın mührü ${ }^{3-4}$ borçlu ŠuDagan'dır. ${ }^{5-6}$ (borç) 10 šeqel arıtılmış gümüştür. ${ }^{7-13}$ (Onu) şehre gittiği zaman ödeyecek. Eğer ödemezse Kārum'un hükmüne göre (faizi) ekleyecektir.

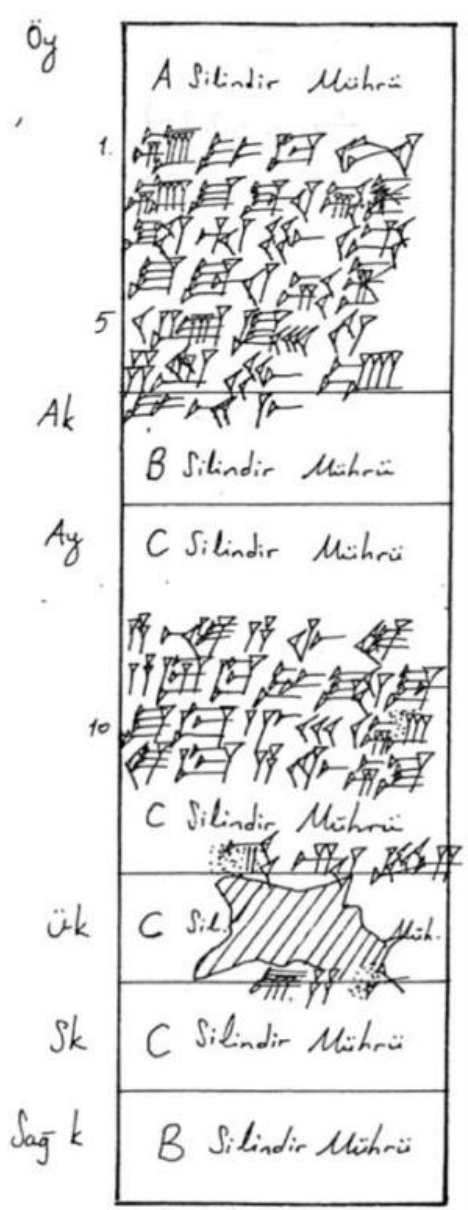

\section{0b. Kt b/k 135b}

\section{Tablet (3.5x4.4x1.6)}

İki Asurlu arasında yapılmış bir borç sözleşmesidir. Borcun şehre gelindiği zaman ödenmesi istenmektedir. Ödenmemesi durumunda, Kārum'un hükmü gereğince, faiz ilâve edileceği kaydedilmiştir. 
Öy. 110 GÍN K[Ù].BABBAR

2 șa-ru-pá-am

3 i-șé-er

4 Šu-Da-gan

5 A-mur-A-šur

Ak. $6 \quad i-s ̌ u i-n u-m[i]$

Ay. $7 \quad$ a-na $a$-lim ${ }^{k i}$

$8 \quad a-l u-k u i-s ̌ a-q a l$

9 šu-ma lá iš-qúl

10 ki-ma a-wa-at

11 kà-ri-im

$12 u$ u-șa-áb

Ük. 13 İGİ $\dot{I}-k u-n i[m]$

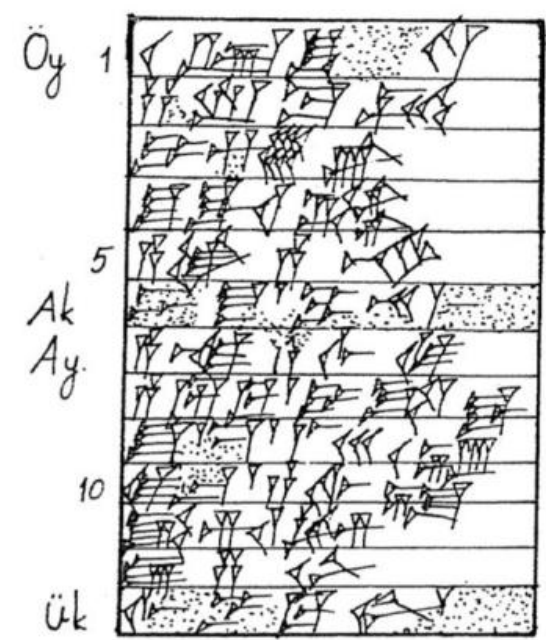

${ }^{1-6}$ Amur-Aššur'un Šu-Dagan'da 10 šeqel arıtılmış gümüşü vardır. ${ }^{6-12}$ Şehre gittiği (geldiği) zaman ödeyecek. Eğer ödemezse, Kārum'un hükmüne göre (faizi) ilâve edecek. ${ }^{13}$ Şahit: İkūnum

\section{Kt b/k 299}

\section{Tablet (3.7x4.6x1.4)}

Asurlular arasında yapılmış bir borç sözleşmesidir. Borcun veriliş tarihi ay ve līmum adı zikredilerek kaydedilmiştir

\begin{tabular}{|c|c|}
\hline Öy. 1 & $1 \frac{1}{3}$ ma-na 2 GÍN \\
\hline 2 & KÙ.BABBAR șa-ru-pá-am \\
\hline 3 & $i$-ṣé-er Wa-qár-ki-ni $[m]$ \\
\hline 4 & $s ̦ u$-ḩa-ri-im ša A-ki-ni[m] \\
\hline 5 & $\grave{u}$ E-na-A-šur Puzur $4-E-n a m$ \\
\hline 6 & DUMU İm-ki-im \\
\hline 7 & Lá-qé-pu-um DUMU Zu-ku-a \\
\hline 8 & $i-\check{s} u$ KÙ.BABBAR $a-n a$ \\
\hline Ak. 9 & İTİ.3.KA[M] i-na Ha-tim \\
\hline Ay. 10 & $i$-ša-qú-lu i qáa-qá-ad \\
\hline 11 & šál-mì-šu-nu ù ke-ni-šu-nu \\
\hline 12 & KÙ.BABBAR ra-ki-is \\
\hline 13 & $\begin{array}{l}\text { İGİ } A \text {-šur-i-mi-tí DUMU } A \text {-šur- } \\
\text { DÜG }\end{array}$ \\
\hline 14 & $\begin{array}{l}\text { İGİ Dan-A-šur DUMU E-nam-A- } \\
\text { šur }\end{array}$ \\
\hline 15 & İGİ $i-d i-{ }^{\mathrm{d}} \mathrm{MUŠ}$ \\
\hline 16 & DUMU E-na-Sú-[en $]$ \\
\hline Ük. 17 & [İT]İ.KAM $M a$-[hu-ur DİNGİR] \\
\hline 18 & li-mu-um \\
\hline
\end{tabular}

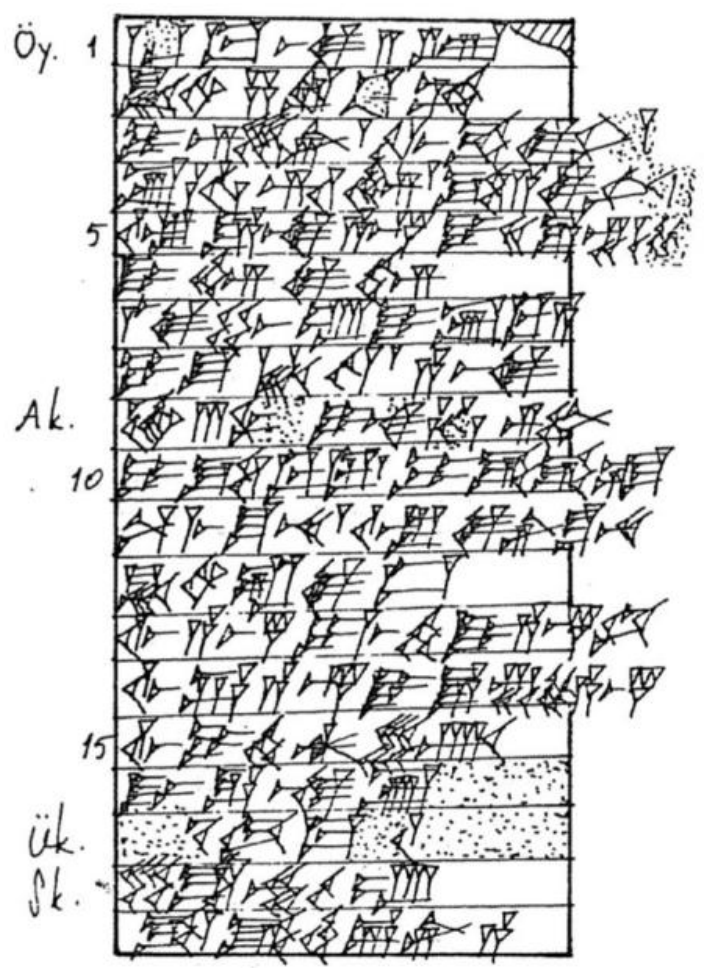


1-8a Zukua'nın oğlu Lā-qēpum'un, İmkum'un oğlu Puzur-Ennam'ın oğlu Ennam-Aššur ve Akīnum'un adamı Waqar-kīnim'de $1 \frac{1}{1} 3$ mina 2 šeqel arıtılmış gümüşü vardır. ${ }^{8 b-10}$ Gümüşü 5 aya (kadar) Hattum'da ödeyecekler. ${ }^{10 b-12}$ Gümüş sağ alanların ve meşru olanların başına bağlanmıştır. ${ }^{13-16}$ Şahitler: Aššur-Ṭāb'ın oğlu Aššur-imittī, Ennam-Aššur'un oğlu Dan-Aššur, Ennam-Suen'in oğlu İdī-Nirah. ${ }^{17}$ Mah[hur-ilī] ay ${ }^{18-19}$ Dan-Ea'nın lìmum vekilliği.

St. 3: Waqar-kīnim, "hakikatin kıymeti" anlamına gelmektedir. Bu türde şahıs isimleri Nuzi metinlerinde çok geçmektedir. Misal verecek olursak: Wa-qár-abī; wá-qar-bēli (AHw, 1460).

St. 9: ina Hattim: Asur kayıtları sıklıkla Hattum'dan söz eder, bazen de terimin bir şehir yerine bir bölge için kullanıldığını ima eden görüşler mevcuttur. J. Lewy mevcut delillerin "Hattum" ile "Hattušaš'1 mı yoksa Boğazköy ile Toroslar arasındaki geniş alanı mı kastettiğini açıkça ortaya koymaya yeterli olmadığını kabul etmiştir. Ancak ona göre Hattum hem bir bölge hem de onu kontrol eden şehir adıyd $1 .{ }^{35}$ Landsberger "ina Hattim" tabirini Hitit metinlerinde geçen "KUR URU Hatti"nin bir karşılığı olarak kabul etmiştir. ${ }^{36}$ Bilgiç ise "Hattum"un, diğer şehirlerin sonuna gelen ve Proto-Hitit zamanına tarihlenen mimasyonlu ek ile sonlanmasına temas ederek, "ina Hattim" ile Hattuš ve civarını kastettiğini kabul etmiştir. Aynı zamanda Koloni Devri'nde henüz Hint-Avrupâi tarzda bir Hitit memleketinin teşekkül etmediğini ve Landsberger'in düşüncesine katılmadığını belirtmiştir. ${ }^{37}$ Dercksen ise, Hattum teriminin Asurlular tarafindan daha spesifik bir coğrafi anlamda Hattuš şehrinin doğrudan siyasi kontrolü altındaki topraklar için bir terim olarak uygulanabileceğini öne sürmüştür. ${ }^{38}$ Barjamovic, Hattum'dan bir bölge olarak bahsedilebileceğini, ancak terimin hiçbir zaman siyasi anlamda geçmediğini belirtir. Ona göre daha fazla kanıt olmadan Hattum ve belki de daha az yaygın olan libbi mātim, az bir ihitimalle 'Orta Anadolu' ve özellikle Purušaddum'un aksine doğu kısmı olarak tercüme edilebilir. Hattum, Purušaddum ve Kaniš, Wahsusana ve Luhuzattiya şehir devletlerinden farklıdır ve Kaniš'in doğusundaki bölgeyle bağlantılıdır. Kısmen Hattum ve libbi mātim arasındaki denkleme bağlı olarak, Durhumit ve Kubumat'ın her ikisi de Hattum'un bir parçası gibi anlaşılmaktadır. ${ }^{39}$ Görüldüğü üzere Hattum'un lokalizasyonu araştırmacılar arasında geçmişten günümüze kadar tartışma konusu olmuştur. Ortaya çıkacak yeni belgeler bu tartışmanın neticelenmesine imkân sağlayabilir. Yine de son mevcut bilgiler işığında Barjamovic'in görüşü kabul edilebilir niteliktedir.

St. 17: "mahhuru" kelimesi "adak kurban, bağış, takdim" anlamındadır (CAD M/I 91). Buradan hareket ederek "warah Mahhur-ilī" kullanımı "Tanrıya kurban sunulan ay anlamında kullanılmış olabilir.

St. 18-19: lìmum Dan-Ea ${ }^{40}$ MÖ 1838 y1lına tarihlenmektedir. Bu da arşivdeki belgelerin uzun bir zaman aralığına ait olduğunu ispatlamaktadır.

\footnotetext{
35 Julius Lewy, "Hatta, Hattu, Hatti, Hattusa and 'Old Assyrian' Hattum”, ArOr, 18, 1950, ss. 366-441.

${ }^{36}$ Benno Landberger, “Kommt Hattum 'Hettiterland' und UattlDum 'Hettiter' in den Kultepe-Tafeln vor?”, ArOr 18/12, 1950, ss. 329-350.

${ }^{37}$ Bilgiç, age., 1953, dn. 10.

${ }^{38}$ Jan Gerrit Dercksen, “ "When we met in Hattush' Trade according to Old Assyrian texts from Alishar and Bogazkoy”, in W. H. van Soldt et al. (ed.), Veenhof Anniversary Volume: Studies Presented to Klaas R. Veenhof on the Occasion of His Sixty-Fifth Birthday (PIHANS 89). İstanbul, 2001, s. 57 vd.

39 Gojko Barjamovic, A Historical Geography of Anatolia in the Old Assyrian Colony Period. CNI Publications 38, Copenhagen, 2011, s. 164.

${ }^{40}$ KEL G 25; REL 135
}

\author{
History Studies \\ www.historystudies.net
}




\section{2a. Kt b/k 154a}

\section{Zarf (4x3x2)}

Öy. 1 KİŠİB Pu-zu-zi-[im]

Silindir mühür A

$2 \quad$ KİŠİB $D a-a-[a]$

3 Kİ̌̆iB En-n[am-A-šùr $]$

4 DUMU Kà-r $[i-a]$

$5 \quad$ DUMU $A-x$-i[ $[\ldots]$

$6 \quad$ Kirık

Ak. $7 \quad$ Kırık

Ay. 8 Kırık

Ük. 9 Kırık

Silindir mühür B

Silindir mühür C

Silindir mühür D

Sk.10 Kırık

${ }^{1}$ Puzuzum'un mührü ${ }^{2}$ Daya'nın mümrü ${ }^{3-5}$ A-x-[...]'nın oğlu Karr[iya]'nın oğlu En[nam-Aššur]'un mührü (Geri kalanı kırık).

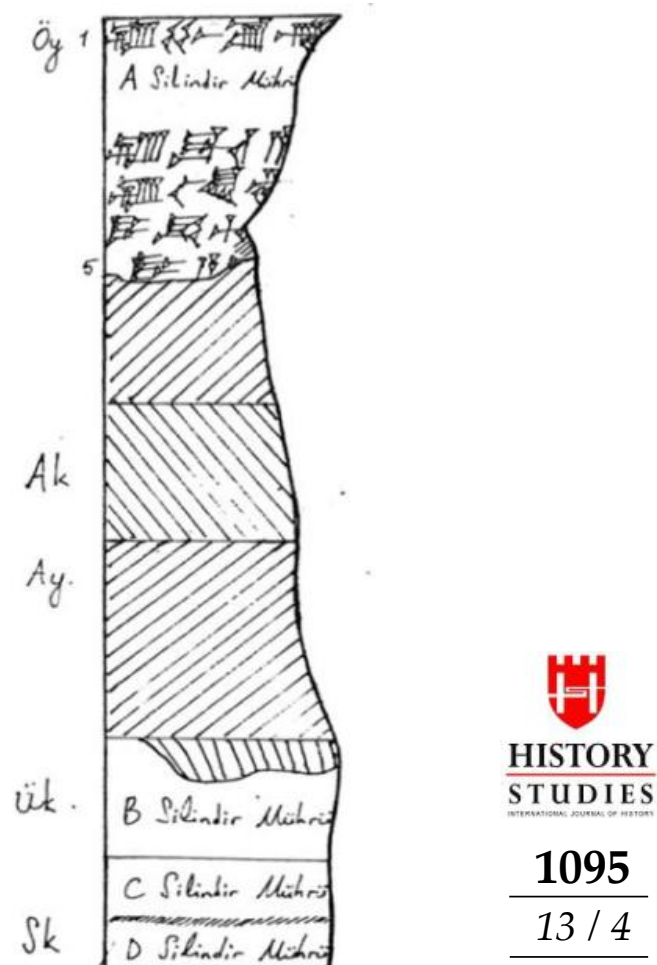

\section{2b. Kt b/k 154b}

\section{Tablet $(4.5 \times 4 \times 5 \times 1.7)$}

İki Asurlu arasında yapılmış bir borç sözleşmesidir. Borcun ödendiği belirtilerek, senedin Asur'da borçluya verileceği ve hükümsüz olacağı kaydedilmiştir. Ancak tüccar tarafindan "tadmiqtu" olarak verilmesi gereken kumaş ve cinsi belirtilmeyen fakat miktarı kaydedilmiş olan emtianın Asû denilen kişiye geri verilmeyeceği şeklinde bir açıklama daha vardır. 


\begin{tabular}{|c|c|}
\hline Öу. 1 & $11 / 2$ ma-na KÙ.BABBAR \\
\hline 2 & ša i-ṣé-er A-sú-ú \\
\hline 3 & $i$-na a-limi ${ }^{k i}$ \\
\hline 4 & {$[K u-k u-l a]-n i m ~ i-s ̌ u-u ́$} \\
\hline 5 & KÙ.BABBAR $\check{s} a-b u t ̦ u p-p u-s ̌ u$ \\
\hline 6 & ša A-sú Ku-ku-la-nim \\
\hline 7 & $i$-na $a$-lim ${ }^{k i}$ \\
\hline 8 & $i-d a-a n-m a$ \\
\hline 9 & $i-d u-a-a k$ \\
\hline
\end{tabular}

Ak. 10 a-na 10 ma-na AN.NA

Ay. $11 \quad k u$-si-tim $\dot{u}^{1} / 3$ GIN.$<$ TA $>15$ SÉ

12 a-na ta-ad-mì-iq-tí-šu

13 a-na A-sú

14 ú-la i-tù-ar

15 İGI $P u-z u-z i-i m$

16 İGI ${ }^{d} E n-l i ́ l-b a-n i$

17 İGİ $D a-a-a$

18 İGİ En-um-A-šùr

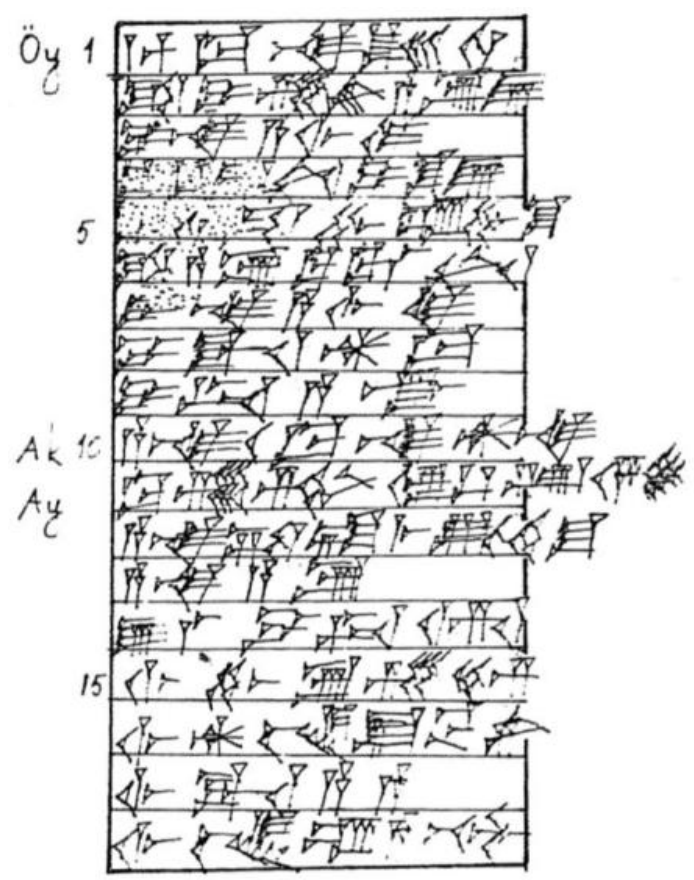

${ }^{1-4}$ Asû'nun üzerinde (bulunan) $11 \frac{1}{2}$ šeqel gümüş Asurlu Kukulānum'undur. ${ }^{5}$ Gümüşe doyurulmuştur. ${ }^{6-9}$ Asû'nun belgesini Kukulānum şehirde (Asur) verecek ve hükümsüz olacak. 10-14 10 mina kalay için elbise ve $1 / 3$ šeqel gümüş 15 utțatum tadmiqtu'su olarak Asû'ya ödenmeyecek. ${ }^{15-18}$ Şahitler: Puzuzum, Enlil-bāni, Daya, Ennam-Aššur.

St. 2: Asû: Asurlu bir şahıs adıdır. "Hekim" anlamına gelen bu kelime burada bir şahıs adı olarak kullanılmış şeklidir (AHw,s.76,2).

St. 11: kusītu : "elbise" (AHw 514). "ku-sí-tum" şeklinde bir kumaş ismi olarak da geçmektedir.

St. 12: tadmiqtu: "faizsiz, ödünç olarak verilen sermaye, mallara karşıllı bir şirkete bir malları zimmetlemek" (AHw, 1300; CAD T 35). Bu kelime için E. Bilgiç, "ticari işlerde, kâr getirmesi esası şart koşularak, patronlar tarafından yanlarında çalışanlara verilen, zarara uğradığı taktirde ise buna iştirak edilmeyen bir nevî borç" olduğunu ifade eder. ${ }^{41}$ Eski Asur metinlerinde tadmiqtum'un Eski Babil'den biraz farklı olarak "itimât edilen her kimseye değeriyle satması için bırakılan mal veya işletmek üzere verilen para" anlamına geldiği de düşünülebilir.

St. 5-6: ina nišrim pānim: "taksit" anlamına gelmektedir. (CAD N, 282). Bizce "nišru" kelimesinin "tasarruf" anlamı ile kullanılması daha uygundur. Zaten metnimizde "nišru" kelimesini "taksit" anlamında kullandığımızda cümlenin bozulduğu açıkça görülmektedir.

\footnotetext{
${ }^{41}$ Emin Bilgiç, “Çivi Yazılı Kaynaklarda Geçen Başlıca Borç ve Ödünç Tabirleri”, DTCF-D, 5/4, 1947, s.432.
} 


\section{3a. Kt b/k 258a}

\section{Zarf (4.5x5x2)}

Öy. Silindir mühür A

1 [KİŠİB Ha-na]-na-ri-im

2 [Kİ̌̀iB A-šùr]-e-mu-qi DUMU İ-di-Sú-en

3 [KİŠİB ...]-A-šùr DUMU Sú-kà-lí-a

Silindir mühür B

$4 \quad 1 \frac{1}{3}$ ma-na KÙ.BABBAR A-mu-ra-am

5 i-șé-er A-mur-A-šùr

Ak. $6 \quad k \grave{a}-r u-u m i-[\check{s} u]$

7 [iš-tù ha-muš-tim]

$8[\check{s} a]$ MAR.TU-ba-ni

Ay. $9 \quad[\grave{u} A-s ̌ u ̀ r-n] a-d a$

$10 \quad$ Kirık

11 Kırık

Ük. 12 Kırık

Sk. Silindir mühür B

Sağ K. Silindir mühür A

${ }^{1}$ [Hana]nārum'un [jnührü], ${ }^{2}$ İdī-Sū'en'in oğlu Aššuremūqū’nin mührü, ${ }^{3}$ Sukkallia'nın oğlu [...-A]ššsur'un mührü 4-6 Kārum'un Amur-Aššur'da 1 1/3 mina Amurru Gümüşü vardır. ${ }^{7-9}$ Amurru-bāni ve [Aššur-n]ādā'nın hamuštum 'undan

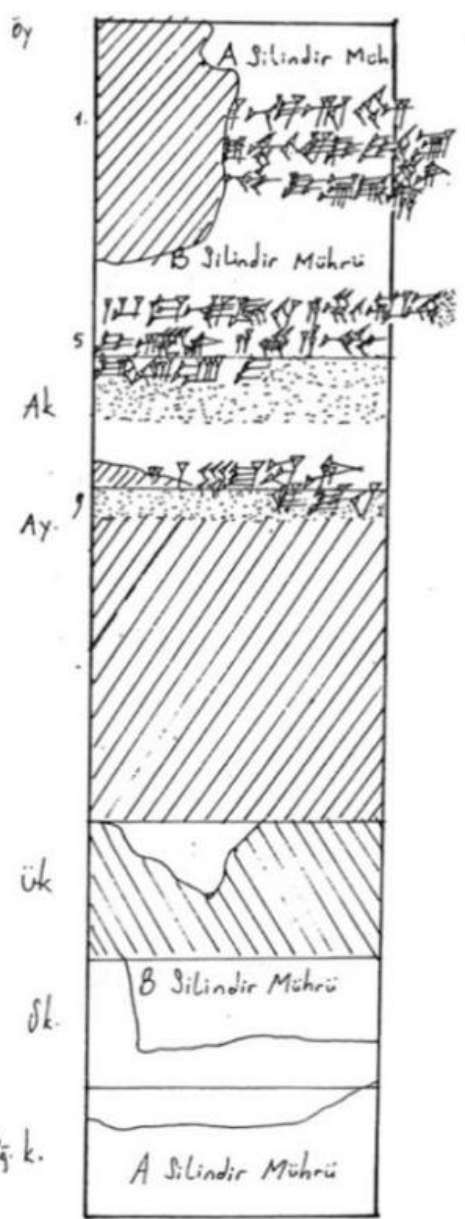

\section{3b. Kt b/k 258b}

\section{Tablet (3.5x3.9xl.6)}

Kārum ile bir Asurlu şahıs arasında yapılmış borç sözleşmesidir. Borcun Amurru Gümüşü olduğu belirtilerek paranın borç veriliş tarihi de hamuštum adı belirtilerek kaydedilmiştir. Ayrıca mukavelede bir şahısın kan parasının ödendiğine dair bir de açıklama vardır. 


$\begin{array}{rl}\text { Öy. } 1 & 11 / 3 \text { ma-na KÙ.BABBAR } \\ 2 & \text { A-mu-ra-am i-șé-er } \\ 3 & \text { A-mur-A-šùr kà-ru-um } \\ 4 & i \text {-šu iš-tù } \\ 5 & \text { ha-muš-tim } \\ 6 & \check{s} a \text { MAR.TU-ba-ni } \\ 7 & \grave{u} A \text {-šùr-na-da }\end{array}$

Ak. $8 \quad 11 \frac{1}{2}$ GIN.TA

Ay. $9 \quad i$ İTİ.1.KAM-im

101 ma-na-im ù-ṣa-áb

11 KÙ.BABBAR gám-ru-um

12 ša da-me-e ša Za-ni-wa-ta

$13 a$-šu-mì En-um-A-šür

14 e-pu-ul

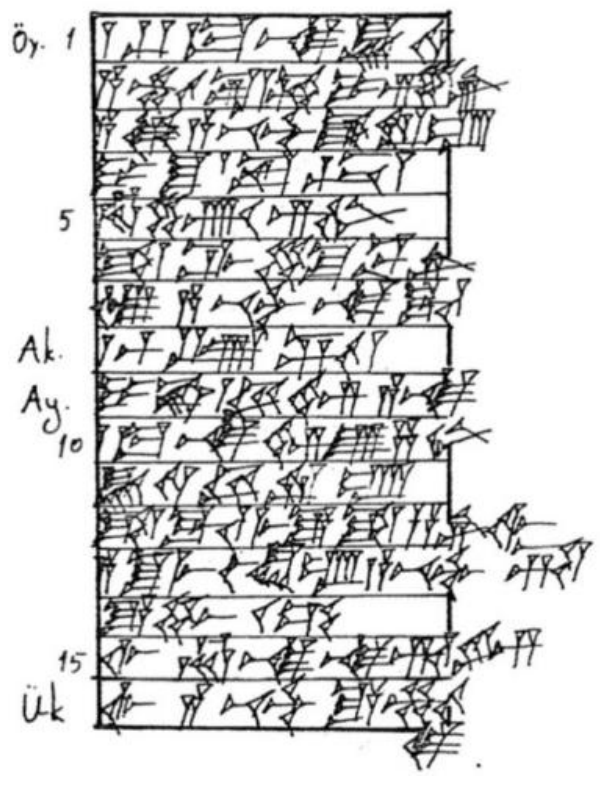

15 İGİ Ha-na-na-ri-im

Ük. 16 İGİ $A$-š̀̀rr-e-mu-qi

1-4a Kārum'un Amur-Aššur'da 1 1 1/3 mina Amurru gümüşü vardır. ${ }^{4 b-7}$ Amurru-bāni ve Aššurnādā'nın hamuštum'undan itibaren ${ }^{8-10}$ her bir ayda 1 mina için $1 \frac{1 / 2}{2}$ šeqel (faizi) ilâve edecek. ${ }^{11-14}$ Ennam-Aššur'un adına Zaniwata'nın kanının masraf parasını o karşıladı (ödedi). ${ }^{15-16}$ Şahitler: Hananarum, Aššur-emūqī.

St. 1-2: kaspam Amurram: “Amurru Gümüşü” (AHw, 46).

St. 12: dâmu: "kan, kan parası, kan dökme ve akraba" gibi anlamlara gelmektedir (CAD D, 75). Bu kelimenin Kültepe metinlerinde "kan parası" manası ile geçişi çok nadirdir. Tespit edilen belgelerde öldürülen kişilerin hayatlarına karşı kan parasının gümüş olarak ödendiği görülmektedir. ${ }^{42}$ Kişisel belgelerin yanında devletler arası yapılan antlaşmalarda da kan parası mevzusuna değinildiği görülmektedir. Günbattı tarafından yayınlanan Kaniš-Asur arasında ve Hahhum-Asur arasındaki, antlaşma metinlerinde öldürülen Asurlulara için kan parası ödenmesi kararlaştırılmıştır. ${ }^{43}$

\title{
Sonuç
}

1949 yılı Kültepe kazılarından ele geçirilen arşive ait 13 tabletin transliterasyon, tercüme ve değerlendirmelerinin yer aldığ 1 bu çalışma, Asurlu tüccarların ve Anadolu'nun yerli halkının başta ekonomik olmak üzere sosyal ve kültürel hayatlarına dair birtakım ipuçlarını barındırmaktadır. Özellikle 13. sırada ele aldığımız Kt b/k 258b envanter numaralı belge Kültepe belgeleri içerisinde çok sık rastlanmayan kan parası uygulamasına yeni bir örnek teşkil etmektedir. Bu belge özellikle bu dönemdeki toplumsal hayat içerisindeki bir uygulamayı yansıtması bakımından önem arz etmektedir. Bunun yanında tabletlerde yer alan tarihleme

\footnotetext{
${ }^{42}$ Salih Çeçen, 1998. "Yeni Delillere Gore Kültepe'de 'Kan Parası'”, H. Erkanal, V. Donbaz \& A. Uguroglu (eds.) Relations between Anatolia and Mesopotamia. (CRRAI 34). Ankara 1998, ss. 291-296; Faruk Akyüz, “Asur Belgelerinde Kan Parası”, Belleten Cilt: 84/Say1: 301, 2020, s. 889-895

${ }^{43}$ Kt. 00/k 06: ve Kt. 00/k 10. Bkz. Cahit Günbatt1, “Kültepe'de Bulunmuş İki Antlaşma Metni”, Belleten C LXIX, (2005), s. 761-766 ve 768-774.
}

\author{
History Studies \\ www.historystudies.net
}


metotları belgelerin düzenlendiği tarihlerin ortaya konulmasını mümkün kılmaktadır. Lìmum tarihlemelerine bakarak belgelerin MÖ 1917-1836 yılları arasında düzenlendiğini söyleyebiliriz. Tabletlerde tarihlemelerin Asur geleneğine uygun olarak lìmum (yıl) ve hamuštum (hafta) esasına göre yapıldığı görülmektedir. Tarihleme usullerinde kısa vâdeli borçlar için sadece hafta adı kaydedilirken, uzun vâdeli borçlar için yıl ismi kullanılmıştır. Kimi zaman da tanrılar adına düzenlenen bayramlar borcun ödeneceği tarih olarak kaydedilmiştir. Bununla birlikte bazı zirai tabirler de borcun vadesini belirtmek üzere kullanılmıștır.

\section{Şahıs Adları}

Abu-šalim

Agua

Akīnum, Puzur-Ennam'ın oğlu

Alili

Amur-Aššur

Amur-İ̌star

Amurru-bāni

Anahšu

Aššur-bāni

Aššur-bēl-awātim

Aššur-emūqīi, İdī-Sū'en'in oğlu

Aššur-idī

Aššur-idī, Mumulānum'un oğlu

Aššur-imittī

Aššur-imittī, Aššur-Ṭāb'ın oğlu:

Aššur-nādā

Aššur-țāb, Ușaria'nın oğlu

Aššur-taklāk

Asû

Atatia

Banaga

Bukanum

Buzia

Dadia 9b: 19.

1: 7 .

11: 4 .

8: 6.

10b: 5; 13a:5; 13b: 3 .

7: 2,10 .

13a: 8; $13 b: 6$.

9a: 4; 9b: 2.

8: 21 .
3: 3 .

13a: 2; $13 \mathrm{~b}: 16$.

2: 3 .

4: 21.

7: 16; 5: 5 .

11: 13 .

4: 3; 13a: 9; 13b: 7.

5: 3.

5: 6.

12b: 1, 6, 13 .

8: 20 .

1: $6 ; 2: 6$.

3: 18 .

7: 17 .

1: 15 . 
Dan-Aššur, Ennam-Aššur'un oğlu

Dan-Ea

Daya

Duduna

Dudupiala

Enlil-bāni

Enna-Suen

Ennam-Anum

Ennam-Aššur

Ennam-Aššur, Karriya'nın oğlu

Ennam-Aššur, Puzur-Ennam'in oğlu

Erati

Hananārum

Hananu

Hanārum İzizam-ilī’nin oğlu

İdaya, Adad-bāni'nin oğlu

İdī-Nirah Ennam-Suen'in oğlu

İdī-Aššur

İkūnum

İkūppīya

İlī-ālum

İlī-Aššur

İlī-bāni, Puzur-Aššur'un oğlu

İlî-nādā

Karriya

Kașșuranum

Kukulānum

Lā-qēpum

Lā-qēpum, Zakua'nın oğlu

Merali

Naram-Zu
11: 14

11: 19.

12a: 2; $12 \mathrm{~b}: 17$.

6a: 2, 6; 6b: 3 .

6a: 1; 6b: 9.

13b: 16 .

1: 14; $2: 9 ; 7: 3$

3: 17 .

3: 4; 9a: 1; 9b: 20; 13b: 13.

12a: 3; 12b: 18 .

11: 5 .

9: 7.

13a: 1; 13b: 15.

3: 8 .

4: 19-20.

5: 13.

11: 15

8: 6.

10a: 1; 10b: 13 .

9a: 5; 9b: 3 .

3: 5 .

1: 4.

5: 4 .

1: 3 .

7: 9.

1: 12 .

12b: 4,6 .

4: 13, 17.

11: 7 .

7: 15 .

3: 7 . 
Niakna

Pilah-İštar

Puzur-Ennam, İmkum'un oğlu

Puzur-ilī

Puzur-İštar

Puzur-Ǐstar, Ašur-malik'in oğlu

Puzur-Nirah

Puzuzum

Šu-Aššur

Šu-bēlim

Šu-Dagan

Šu-İštar

Sukkallia X-Aššur'un babası

Țābi-Aššur

Uzua

Waqar-kīnim

Zaniwata

Zizia

Zur-dīni

\section{Hafta Eponimleri (Hamuštum'lar)}

Agua ve Banaga'nın oğlunun hamuštumu

Alili ve İdī-Aššur'un hamuštumu

Amurru-bāni ve Aššur-nādā’nın hamuštumu

Aššur-imitti ve Aššur-taklāk’ın hamuštumu

Banaga'nın oğlunun hamuštumu

Hananu ve Naram-Zu'nun hamuštumu

Ușur-ša-İštar'ın hamuštumu 6b: 10 .

6a: 7; 6b: 4 .

11: 5 .

8: 22.

8:4.

$8: 3$.

4: 9.

12a: $1 ; 12 b: 15$.

2: 13 .

5: 12 .

10a: 2, 4; 10b: 4 .

3: 23

13a: 3.

2: 4.

2: 14 .

11: 3

13b: 12 .

4: $2,13,18$.

6a:3; 6b: 8 .

1: 5-7.

8: 5-6.

13a: 7-9; 13b: 5-7.

5: 5-7.

2: $5-6$

3: 6-8.

2: 5-7. 


\section{Ay Adları}

Mahhur-ilī

Qarrātum

Tīnati
11: 17

2:7.

4: 10 .

\section{Yıl Eponimleri (Līmum'lar)}

Dan-Ea

11: $18-19$.

Enna-Suen

2: 8-9.

kakkabānum Šu-Ǐštar

3: $22-23$.

Puzur-Nirah

4: 8-9.

\section{Kisaltmalar}

AHw Von Soden, W., Akkadisches Handwörterbuch

ArAn Archivum Anatolicum

ArOr Archiv Orientâlni

CAD The Assyrian Dictionary of the Oriental Institute of the Universtiy of Chicago,

DTCF-D Ankara Üniversitesi Dil ve Tarih-Coğrafya Fakültesi Dergisi

KEL A The Kültepe Eponym List A. Bkz. Veenhof, K. R. 2003. The Old Assyrian List of Year Eponyms from Karum Kanish and its Chronological Implications. (TTKY $\mathrm{Vl} / 64)$, Ankara.

KEL G The Kültepe Eponym List G. Bkz. Günbatt1, C., 2008. "An Eponym List (KEL G) from Kültepe", AoF, 35/1, ss. 103-132.

REL Revised Eponym List. Bkz. Barjamovic, G., T. Hertel and M. T. Larsen, 2012. Ups and Downs at Kanesh - Observations on Chronology, History and Society in the Old Assyrian Period. Leiden.

\section{Kaynakça}

AKYÜZ, Faruk, “Asur Belgelerinde Kan Parası”, Belleten, Cilt: 84/Say1: 301, 2020, ss. 887-906.

BALKAN, Kemal, "The Old Assyrian Week", Studies in Honor of Benno Landsberger on His Seventy-Fifth Birthday, (University of Chicago.Oriental Institute.Assyriological studies;no.16) 1965, ss. 159-174.

BARJAMOVIC, Gojko, A Historical Geography of Anatolia in the Old Assyrian Colony Period. CNI Publications 38, Copenhagen 2011. 
BARJAMOVIC, Gojko - Thomas Hertel - Trolle Larsen, Ups and Downs at Kanesh Observations on Chronology, History and Society in the Old Assyrian Period. Leiden 2012.

BAYRAM, Sebahattin, "Kültepe Tabletlerinde Geçen Yeni bir Vâde İfâdesi ve Çıkan Neticeler", X. Türk Tarih Kongresi, II, Ankara 1990, ss. 453-462.

BAYRAM, Sebahattin, "Kültepe Tabletlerinde Geçen Vergiler ve Özellikleri”, DTCF-D, Cilt 36, Say1 1-2, 1993, ss. 1-13.

BİLGIÇ, Emin, "Çivi Yazılı Kaynaklarda Geçen Başlıca Borç ve Ödünç Tabirleri”, DTCF-D, $5 / 4,1947$, ss. 419-454

BİLGIÇ, Emin, Kapadokya Metinlerinde Geçen Yerli Apellatifler ve Bunların Eski Anadolu Dilleri İçerisindeki Yeri. Ankara 1953.

ÇEÇEN, Salih, "Yeni Delillere Gore Kültepe'de 'Kan Parası"”, H. Erkanal, V. Donbaz \& A. Uguroglu (eds.) Relations between Anatolia and Mesopotamia. (CRRAI 34). Ankara 1998, ss. 291-296.

ÇEÇEN, Salih - Faruk Akyüz, “1949 Yılı (Kt. b/k) Kültepe Kazısından Aššur-țab’a Ait Bir Grup Borç Mukavelesi”, Akademik Tarih ve Düşünce Dergisi, 5 (17 Ek Özel Sayı), 2018, ss. 128 .

ÇEÇEN, Salih - Faruk Akyüz, "Kültepe'den Bazı Ticari Belgeler ve Bunların Değerlendirilmesi”. ArAn, 13/2, 2019, ss. 101-122.

ÇEÇEN, Salih - Koray Toptaş, “1949 Yılı (Kt. bk) Kültepe Kazısından Karriya’ya Ait Bir Grup Borç Sözleşmesi”, Tarihin İzinde Bir Ömür: Prof. Dr. Nuri Yavuz'a Armağan, Ankara 2019, ss. 312-326.

ÇEÇEN, Salih - Lütfi Gütkan Gökçek, "Kültepe Tabletlerinde Yerli Tarihleme Usulleri”, Studies in Honor of Hayat Erkanal Cultural Reflections, 2006, ss. 218-221.

DERCKSEN, Jan Gerrit, “When we met in Hattush' Trade according to Old Assyrian texts from Alishar and Bogazkoy", in W. H. van Soldt et al. (ed.), Veenhof Anniversary Volume: Studies Presented to Klaas R. Veenhof on the Occasion of His Sixty-Fifth Birthday (PIHANS 89). İstanbul 2001, ss. 39-66.

GÜNBATTI, Cahit, “Kültepe'de Bulunmuş İki Antlaşma Metni”, Belleten, C LXIX, 2005, ss. 759-780.

GÜNBATTI, Cahit, “An Eponym List (KEL G) from Kültepe”, AoF, 35-1, 2008, ss. 103-132.

GÜNBATTI, Cahit, Kültepe Kaniş, Anadolu'da Illk Yazl, İlk Belgeler. Kayseri Büyükşehir Belediyesi Kültür Yayınları, Kayseri 2017.

LANDBERGER, Benno, “Kommt Hattum 'Hettiterland' und UattlDum 'Hettiter' in den KultepeTafeln vor?", ArOr 18/1-2, 1950, 329-350.

LARSEN, Mogens Trolle, Ancient Kanesh: A Merchant Colony in Bronze Age Anatolia. Cambridge: Cambridge University Press, 2015.

LEWY, Hildegard - Julius Lewy, The Origin Of The Week And The Oldest West Asiatic Calendar, Hebrew Union College Annual (HUCA) Vol. 17, 1942-43.

LEWY, Julius, "Hatta, Hattu, Hatti, Hattusa and 'Old Assyrian' Hattum”, ArOr, 18: 1950, ss. 366-441. 
MICHEL, Cecile, Old Assyrian Bibliography of Cuneiform Texts, Bullae, Seals and the Results of the Excavations at Assur, Kültepe/Kanis, Acemhöyük, Alishar and Bogazköy. OAAS 1 (Old Assyrian Archives Studies 1). PIHANS 97, Leiden 2003.

VEENHOF, Klaas Roelof, "Kanesh. An Assyrian Colony in Anatolia”, CANE 2 (Civilizations of the Ancient Near East 2), 1995, ss. 859-871.

VEENHOF, Klaas Roelof, "The Old Assyrian Hamuštum Period: A seven-day week", JEOL 34 (Jaarbericht van het Vooaziatisch-Egyptisch Genootschap Ex Oriente Lux), 1996, ss. 5-26.

VEENHOF, Klaas Roelof, The Old Assyrian List of Year Eponyms from Karum Kanish and its Chronological Implications. (TTKY Vl/64), Ankara 2003. 


\section{Summary}

The documents belonging to the Assyrian Trade Colony Period have an important place in Anatolia's culture, economy, social and political history because of that documents are the first written materials of Anatolia. Although this period represents a period of approximately 220 years, it should be said that the documents obtained mostly belong to a time period of 40-50 years. When these tablets, which are called Kültepe Tablets and written in the Old Assyrian dialect, are examined, it is reached to valuable information about the Assyrian merchants and the native people of Anatolia. In this respect, the Kültepe Tablets have a key role in filling the gaps in the cultural life and partly in the political history of Colonies Age in Anatolia and the Ancient Assyrian State. However, the emergence of the tablets happened after the great palace archives were unearthed in Mesopotamia. The interest in Kültepe increased with smuggled to abroad the tablets which were illegally excavated by the villagers and called Cappadocia Tablets, On this occasion, four excavations were carried out in the mound between 1893 and 1925 by foreign researchers, but no tablets were found in the first three of these excavations. The discovery of the tablets, on the other hand, was realized with the discovery of about a thousand tablets in the fourth excavation carried out by Hrozny, who evaluated the informations from the villagers and focused on the field at the foot of the mound. Thus, Kaniš Karum, inhabited by Assyrian merchants, was discovered. These tablets found by Hrozny were published by the Assyrologists and it was understood that the tablets were archives of merchants and they reflected the commercial and legal procedures of the people living in the houses there.

The first systematic excavations in the mound were started in 1948 under the presidency of Tahsin Özgüç on behalf of the Turkish Historical Society and the General Directorate Of Ancient Arts and Museums. Tahsin Özgüç, with his excavations in the first two years, revealed that Karum consists of four layers and that Assyrian merchants settled here in the second layer where the tablets were unearthed. In addition, it has been understood that not all of these documents belong to the Assyrians and that some of the documents unearthed belong to the merchants who are natives of Anatolia.

In this study, thirteen tablets which were found from the 1949 Kültepe excavations, will be discussed. twelve of the documents are about the debt contract and ones is about the payment of a service fee. While ten of the debt contracts were arranged between the Assyrians, ones was between the Assyrian merchant and the Kārum institution, and one was between an Assyrian merchant and an Anatolian. It is seen from the documents that the Assyrian merchant gave loans to both Assyrians and Anatolians. By looking at limum datings, it shows that the documents were arranged between 1917-1836 BC.

It is seen that the dates on the tablets were made on the basis of limum (year) and hamuštum (week) in accordance with the Assyrian tradition. In the dating methods, while the week name is only recorded for shortterm debts, the year name is used for long-term debts. In the documents, the period of payment of the debt is mostly expressed in weeks. Sometimes, the holidays made in the name of the gods were recorded as the date of payment of the debt. However, some agricultural terms are also used to indicate the maturity of the debt. In addition, the limum lists discovered in Kültepe enable the chronological dating of the tablets and thus the chronology of the colonial period can be revealed.

\section{History Studies

